\title{
IS THE BLUFF ENOUGH? EXAMINING THE EFFECT OF DIFFERENT VARIANTS OF FALSE EVIDENCE ON FALSE CONFESSIONS
}

\author{
by \\ Leah Hamovitch \\ Honours Bachelor of Arts in Psychology, McGill University, June 2015
}

\author{
A thesis presented to Ryerson University \\ in partial fulfillment of the \\ requirements for the degree of \\ Master of Arts \\ in the program of
}

Psychology

Toronto, Ontario, Canada, 2019

(C) Leah Hamovitch 2019 


\section{AUTHOR'S DECLARATION FOR ELECTRONIC SUBMISSION OF A THESIS}

I hereby declare that I am the sole author of this thesis. This is a true copy of the thesis, including any required final revisions, as accepted by my examiners.

I authorize Ryerson University to lend this thesis to other institutions or individuals for the purpose of scholarly research.

I further authorize Ryerson University to reproduce this thesis by photocopying or by other means, in total or in part, at the request of other institutions or individuals for the purpose of scholarly research.

I understand that my thesis made be made electronically available to the public. 
Is The Bluff Enough? Examining the Effect of Different Variants of False Evidence on False Confessions

\author{
Master of Arts, 2018 \\ Leah Hamovitch \\ Psychology \\ Ryerson University
}

\begin{abstract}
At present, the majority of false confessions are the result of psychologically manipulative interrogation tactics. Interrogators may use the false evidence ploy or the bluff ploy to elicit confessions. Unfortunately, research suggests that these interrogation tactics increase the risk of false confessions. At this time, research on the differential impact of the false evidence ploy and the bluff ploy is inconclusive, and there is little known about whether certain variants of false evidence are differentially powerful in eliciting false confessions. The present study examined the following: 1) the differential effect of the false evidence ploy and the bluff ploy on false confessions, and 2) the differential effect of three variants of false evidence on false confessions. The present study used a 2 (ploy: false evidence vs. bluff) by 3 (evidence variant: photograph vs. physical vs. eyewitness) between-subjects design. Participants $(\mathrm{N}=218)$ completed a logical reasoning task on a computer and were accused of violating the experimental protocol by pressing the space bar and seeing the answer. Participants were either shown faked (false) evidence, or told this evidence could be examined at a later date (bluff), and were then prompted to sign a confession statement. Results demonstrated that participants in the photograph evidence condition were more likely to falsely confess and to internalize guilt than participants in the physical evidence condition and eyewitness testimony condition. Results also demonstrated that participants in the false evidence condition were more likely to falsely confess and internalize guilt than participants in the bluff condition. The policy implications of these findings are discussed.
\end{abstract}




\section{Acknowledgements}

I would first like to sincerely thank my supervisor, Dr. Tara Burke, who encouraged me to undertake a challenging, but rewarding, project, and who has supported me throughout the last two years. Her constant support and guidance has allowed me to pursue my passion for psychology and law, and to grow both academically and professionally. I would also like to thank Dr. John Turtle for his invaluable insight throughout the design and implementation of this thesis, and for always encouraging my research interests.

Thank you to the members of the Psychology and Law (PAL) lab, Emma Rempel and Lesley Zannella, for answering my countless questions, for providing me with guidance and encouragement, but mostly, for being incredible PALS. Thank you for the chats, the laughs, the snacks, and for making our workplace a genuinely fun and supportive place to be.

Next, I would like to thank my parents and my role models, Pam and Greg Hamovitch. They are gracious, supportive, and patient, and always eager and curious to hear all about my day at school, even at age 26 . They are my cheerleaders, my editors, my confidants, and so much more. Lastly, thank you to my partner, Shane Rodak, for his unconditional love and patience, and his ability to make me smile and laugh when I need it most. 
Table of Contents

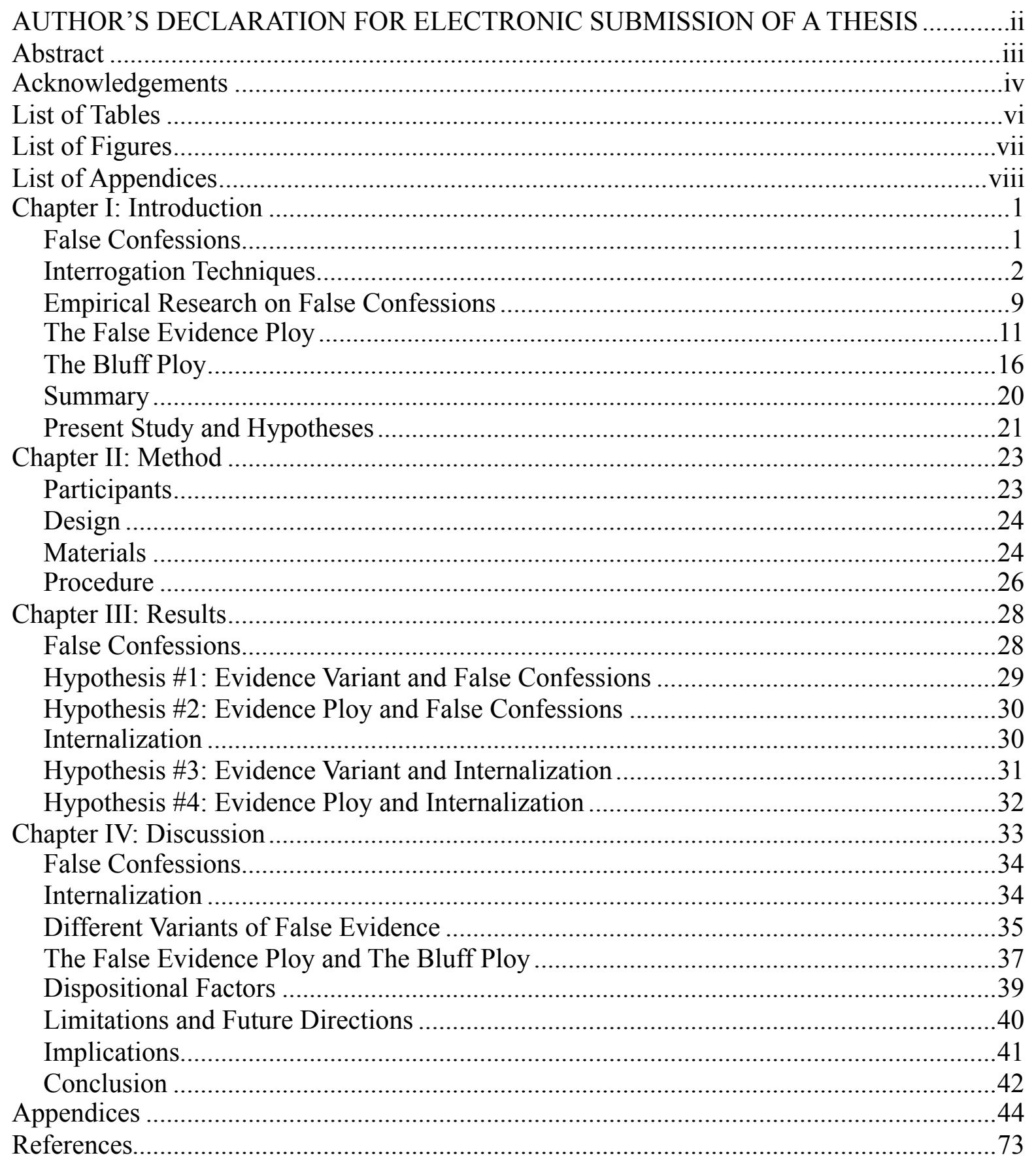




\section{List of Tables}

Table 1: Evidence variant and percentage of false confessions and internalization ..............31

Table 2: Evidence ploy and percentages of false confessions and internalization .................32 


\section{List of Figures}

Figure 1: Percentage of false confessions by evidence variant .........................29

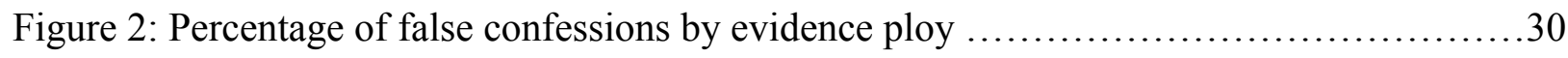




\section{List of Appendices}

Appendix A: The Gudjonsson Compliance Scale

Appendix B: The Creative Experiences Questionnaire ....................................45

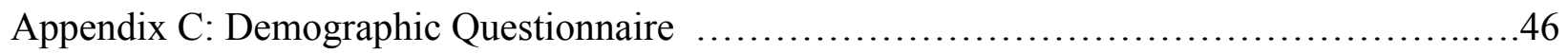

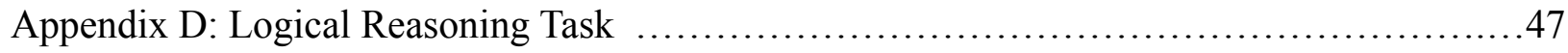

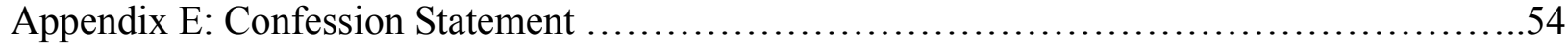

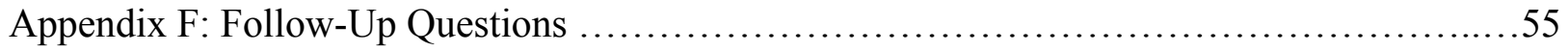

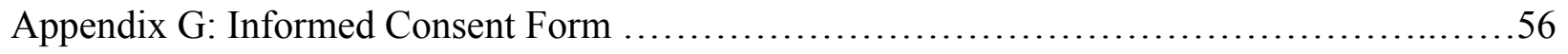

Appendix H: False Photograph Evidence Script …....................................60

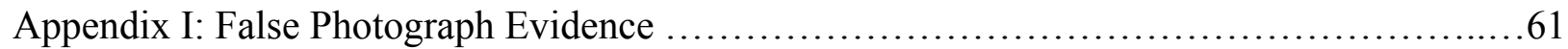

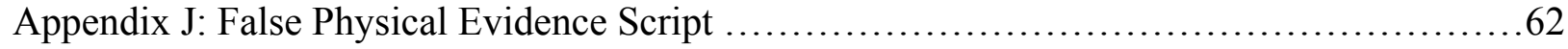

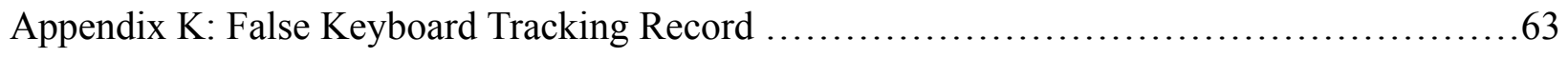

Appendix L: False Eyewitness Testimony Script ….....................................64

Appendix M: Sample Research Assistant Note ….....................................66

Appendix N: Bluffed Photograph Evidence Script …....................................66

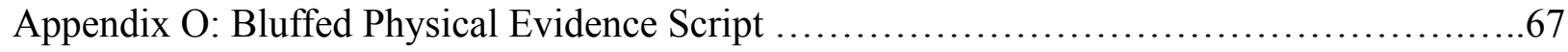

Appendix P: Bluffed Eyewitness Testimony Script …...................................68

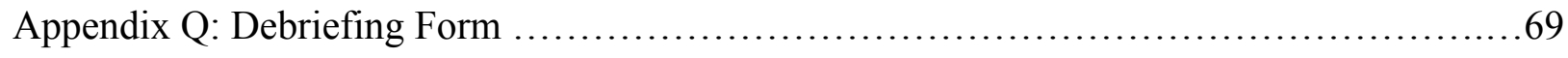

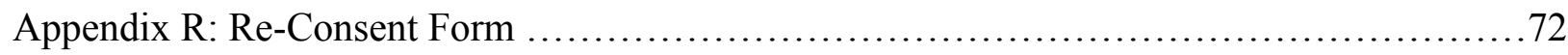




\section{Chapter I: Introduction}

Is The Bluff Enough? Examining the Effect of Different Variants of False Evidence on False Confessions

Since 1989, approximately 2,500 wrongful convictions have been exposed in Canada and the United States, either through DNA profiling or through the discovery of exculpatory evidence (Innocence Canada, 2019; The National Registry for Exonerations, 2019). To date, these wrongfully convicted individuals have served a cumulative total of 21,500 years in prison, with an average sentence of 14 years (Innocence Canada, 2019; The National Registry for Exonerations, 2019). With the advent of DNA testing, we are now able to establish factual innocence, and, as a direct result, thousands of innocent individuals have been able to walk free from prison after years of unjust incarceration (Drizin \& Leo, 2004). At the same time, DNA profiling has allowed researchers, legal scholars, and activists to expose the fact that wrongful convictions occur with troubling regularity in North America and worldwide (Leo, 2005).

\section{False Confessions}

Investigations into these miscarriages of justice have identified false confessions as one of the leading contributing factors to wrongful convictions (The Innocence Project, 2019). A false confession occurs when an innocent suspect admits guilt for a crime that they did not commit (Kassin, 2014). According to The Innocence Project, approximately 25\% of individuals who were wrongfully convicted and later exonerated by DNA evidence, had falsely confessed to a crime. It is important to note, however, that this sample does not include false confessions for which DNA evidence was not available, for lesser crimes that involve less post-conviction 
attention, and that were rejected by police or prosecutors; therefore, these instances likely represent just the tip of the iceberg (Drizin \& Leo, 2004).

There are three types of false confessions that are well established in the literature, each of which contains a distinct set of precursors, motivations, and psychological consequences (Gudjonsson, 1999). A voluntary false confession occurs when an innocent suspect confesses to a crime that they did not commit without being pressured or prompted by police. A compliant false confession occurs when a suspect, who knows that they are innocent, acquiesces to the demand for a confession as an act of behavioural compliance. Research suggests that suspects may confess as an act of behavioural compliance when they perceive the short-term benefits of confessing to outweigh the long-term consequences, or when they feel trapped by the weight of the evidence against them (Perillo \& Kassin, 2010). Lastly, an internalized false confession occurs when an innocent suspect, after exposure to suggestive interrogation tactics, comes to question their involvement in the crime (Kassin, 2017). Research suggests that the memory distrust syndrome may underlie internalized false confessions, such that suspects develop a profound distrust of their memory recollections, and enter a heightened state of confusion and suggestibility, such that they come to believe that they committed the crime (Kassin, 1997).

\section{Interrogation Techniques}

Although a significant number of false confessors are under the age of eighteen, intellectually disabled, or both (The Innocence Project, 2019), many false confessors do not display any dispositional risk factors; instead, they are victim to psychologically manipulative interrogation tactics, such as lengthy interrogations, prolonged isolation, feigned sympathy, and the presentation of false evidence, which increases their likelihood to falsely confess (Redlich \& 
Meissner, 2009). To date, the majority of reported false confession cases are the result of innocent suspects being wrongly targeted and subjected to psychologically manipulative police interrogations (Sangero, 2018).

The Reid Technique. A commonly used interrogation procedure in North America is the Reid technique (Kassin, Redlich, Alceste, \& Luke, 2018). The Reid technique prescribes a ninestep approach that uses psychologically sophisticated methods designed to aid an interrogator in eliciting a confession from a suspect (Gohara, 2006). The Reid technique is founded on the premise that a suspect will not confess unless they are led to to believe that doing so is in their best interest. Therefore, it is the goal of the interrogator to persuade the suspect that the benefits of confessing are high, and that the consequences of confessing are low (Gohara, 2006).

The Reid technique begins with a pre-interrogation interview, whereby investigators ask non-accusatory questions and observe the suspect's verbal and non-verbal behaviours, such as posture, eye contact, and fidgeting, to determine whether the suspect is being truthful or deceptive (Kassin, 2017). This initial judgement of deception is critical, as it determines whether the suspect will be released or interrogated further (Kassin, 2017). Although interrogation training manuals suggest that investigators can be trained to detect deception with extremely high levels of accuracy (Inbau, Reid, Buckley, \& Jayne, 2001), psychological research has consistently shown that, in terms of lie detection, untrained individuals perform at no better than chance level (Bond \& Depaulo, 2006), and that expert training produces minimal or no improvements (Hartwig \& Bond, 2011). Importantly, research suggests that police, judges, and polygraph examiners perform only slightly better, if at all, than laypersons, albeit with a bias toward perceiving deception, and with higher levels of confidence (Kassin \& Fong, 1999; 
Meissner \& Kassin, 2002). These confidently held judgements of deception are dangerous insofar as they decrease investigators' motivation to investigate alternate suspects or theories of the case, thus increasing the likelihood that an innocent suspect will be subjected to an aggressive and confrontational interrogation (Leo \& Drizin, 2011).

The phenomenon of interrogator bias has been identified as a leading cause of wrongful convictions (Trainum, 2016). Oftentimes, investigators will enter the interrogation room with certain expectations and assumptions about the suspect and the crime that is being investigated, and thus the potential for confirmation biases is inherent in the interrogation process (Gudjonsson, 1999). Research has shown that, once interrogators form an initial impression of a suspect, they will subconsciously seek information and behaviours that confirm their opinion, and ignore evidence that might contradict their theory of the case (Kassin, 2014). In a laboratory experiment illustrating the dangers of investigator biases, Kassin, Goldstein, and Savitsky (2003) had participants, who were either guilty or innocent of a mock crime, questioned by interrogators who were led to believe that they were either guilty or innocent. The results demonstrated that interrogators who presumed guilt conducted more coercive interrogations, asked harsher and more incriminating questions, and applied more pressure to get a confession — particularly when paired with innocent participants. Specifically, interrogators interpreted innocent participants' denials as proof of a guilty person's resistance, and subsequently intensified their efforts to elicit a confession (Kassin, Goldstein \& Savitsky, 2003). Therefore, misclassifying innocent suspects is the first and most consequential error that police can make in the investigation process (Leo \& Drizin, 2011). 
Once the investigator has determined that the suspect is deceptive and guilty, the goal then becomes to elicit a confession from the suspect, which is accomplished through an interrogation (Kassin et al., 2010). The Reid technique interrogation is an accusatory and guiltpresumptive process, whereby police are advised to isolate the suspect in a small, windowless room for a lengthy period of time, in order to increase anxiety, fear, and the incentive to escape (Kassin et al., 2010). An analysis of proven false confession cases revealed that $34 \%$ of interrogations lasted between 6-12 hours, and 39\% lasted between 12-24 hours (Drizin \& Leo, 2004). During this time, suspects tend to experience fatigue, sleep deprivation, and feelings of helplessness (Kassin et al., 2010). The lengthy interrogation process may compromise the suspect's decision-making capacity, such that the decision to falsely confess is based on the interrogator's ability to manipulate the suspect's perceptions and understanding of their present situation, and to bias their evaluations of the choices presented to them (David \& O'Donohue, 2004; Ofshe \& Leo, 1997).

Interrogations may use minimization and/or maximization techniques in order to yield a confession. Minimization refers to a process whereby the interrogator acts in a friendly and sympathetic manner in order to minimize the appearance of moral responsibility, and to lessen the perceived punitive consequences of confessing (Kassin, 2017). The interrogator may tell the suspect that their crime is justifiable and understandable, and that it will not produce adverse consequences; in doing so, the interrogator implies to the suspect that leniency in punishment is forthcoming upon confession (Kassin, 2017). Conversely, maximization involves the use of intimidation and scare tactics, whereby the interrogator confronts the suspect with unrelenting accusations of guilt, refuses to accept denials, and may present false evidence, in order to shift 
the suspect's mentality from confident to hopeless (Kassin et al., 2010). The interrogator ultimately sets up a situation in which the suspect sees confessing as a rational choice and the most effective means of escape (Ofshe \& Leo, 1997). Once the interrogator has persuaded the suspect to admit guilt, they will convert that admission of guilt into a written confession that outlines the suspect's involvement in the crime, as well as specific details about the crime (Kassin et al., 2010).

One could argue that the risk of false confessions can be tolerated to the extent that involuntary or coerced confessions are detected and ultimately corrected in court by judges and juries (Kassin, Appleby, \& Perillo, 2010). Unfortunately, however, research suggests that confession evidence — regardless of the voluntariness of the confession — is powerful and persuasive, such that it often provides a sufficient basis for jury convictions (Kassin, 2014). Researchers and legal scholars consider confession evidence to be the most damning form of evidence, as it is inherently prejudicial and highly detrimental to a defendant — even when the forensic evidence is contradictory or nonexistent, even if it is the product of a coercive interrogation, and even if it is deemed inadmissible by a judge (Kassin \& Neumann, 1997; Drizin \& Leo, 2004). Because confession evidence often appears authentic and voluntary, its presence sets into motion an almost irrefutable presumption of guilt, such that jurors are more strongly impacted by a confession than any other form of evidence (e.g., eyewitness testimony, forensic evidence; Kassin \& Neumann, 1997). In fact, research suggests that approximately $81 \%$ of false confessors are ultimately convicted by a jury (Drizin \& Leo, 2004).

Kassin and Sukel (1997) had mock jurors read transcripts of a murder trial containing confession evidence that was elicited in a high or low pressure interrogation, and that was ruled 
admissible or inadmissible by a judge. Results demonstrated that, when presented with a confession that was produced by a coercive interrogation, mock jurors responded in a legally prescribed manner, such that they determined that the statement was not given willingly, and stated that it did not affect their verdicts. In the end, however, the mock jurors were still more likely to render a guilty verdict in these cases. These findings suggest that confession evidence is highly deleterious to a defendant, and that jurors may not dismiss this evidence even when it is logically and legally appropriate to do so (Kassin \& Sukel, 1997). Concerningly, research has demonstrated a similar pattern with police, suggesting that police are poorly trained about the dangers of interrogations, the causes of false confessions, or how to avoid false confessions (Leo \& Ofshe, 1998).

In 1989, five innocent young boys were convicted of attacking and raping a jogger in Central Park, after each of the boys falsely confessed to their involvement in the brutal attack. Despite the boys' innocence, a group of police officers and interrogators deceived the young boys into believing that they were providing statements as witnesses, rather than as suspects, that they would be permitted go home once they provided taped interviews, and that the other suspects had already confessed and implicated them in the crime (Gohara, 2006). Eventually, after several hours of being interrogated, deceived, and stripped of parental support or legal advice, each of the boys provided taped confession statements. These confession tapes, which included the boys' gruesome re-telling, and even reenactment, of the attack, persuaded two trial juries of the boys' guilt, such that they were convicted and sentenced to time in prison. In 2002, the boys were exonerated, when the true perpetrator confessed to committing the crime. Infamously known as the Central Park Five case, this case exemplifies how police pressure, 
deception, and manipulative interrogation techniques can produce false confessions and wrongful convictions.

The use of psychologically manipulative techniques, such as the Reid technique, is considered legally admissible, and some police investigation manuals suggest that using deceitful tactics is a valuable strategy and a necessary means for eliciting confessions (Kassin, 2017). The use of the Reid technique has been documented in naturalistic observational studies (Leo, 1996), surveys of North American investigators (Kassin et al., 2007), observations of taped interrogations (Ofshe \& Leo, 1997), and controlled laboratory studies (e.g., Horselenberg et al., 2006). These interrogation techniques are widely used by investigators in North America, and have shown to be $40 \%$ - 75\% effective in yielding confessions (Russano et al., 2005). The issue, however, lies in the fact that these techniques, while effective in capturing true perpetrators, are equally as effective in yielding false confessions from innocent suspects.

The PEACE Model. While accusatorial methods, such as the Reid technique, are commonly employed in Canada and the United States, a number of European countries have banned components of this form of interrogation, including the use of heavy pressure and deception, and the presentation of false evidence (Meissner et al., 2014). Alternatively, these countries utilize information-gathering methods, such as the PEACE model, in which investigators establish rapport with the suspect, use direct and positive confrontation, and ask open-ended, exploratory questions, in order to obtain the suspect's version of events (Meissner et al., 2014).

The PEACE model stands for Preparation and Planning, Engage and Explain, Account, Closure, and Evaluate (Kassin, Appleby, \& Perillo, 2010). It was developed by a team of 
psychologists, academics, police practitioners, and lawyers, specifically with the intent to minimize the occurrence of false confessions (Shawyer, Milne \& Bull, 2009). While the singular goal of accusatorial methods is to elicit incriminating statements that assist the State in its prosecution of the defendant (Drizin \& Leo, 2004), information-gathering methods focus on obtaining accurate information and establishing the truth (Kassin et al., 2010; Meissner et al., 2014). A meta-analysis comparing these two interrogation styles, in both laboratory settings and in real-world contexts, demonstrated that information-gathering methods are more diagnostic, such that they elicit a greater proportion of true confessions, while protecting against the incidence of false confessions (Meissner et al., 2014). Research on the efficiency and ethical approach of the PEACE model resulted in a push for Canada and the United States to adopt this alternative interrogation method, and, as a result, this technique has gained popularity in both Canada and the United States (Meissner et al., 2014).

\section{Empirical Research on False Confessions}

Kassin and Kiechel (1996) were the first to develop an ethical paradigm to elicit false confessions in a laboratory setting. They created the "ALT-key paradigm" (also referred to as the "computer crash paradigm"), whereby participants are falsely accused of clicking the ALT button - a prohibited button that participants were warned would cause the computer to crash and the data to be lost if pressed. Following several direct accusations made by the researcher, participants were asked to signed a confession statement, admitting that they were responsible for pressing the ALT-key and crashing the computer. Results demonstrated that $69 \%$ of participants agreed to sign the confession, and 28\% internalized guilt for the event. Klaver, Lee, and Rose (2008) used this paradigm to determine whether minimization and maximization 
differentially impact false confession rates, and found that participants in the minimization condition were 4.31 times more likely to falsely confess than those in the maximization condition. The results of these studies demonstrate that false confessions can be readily elicited in a laboratory setting via false accusations, interrogative pressure, and psychological manipulation (Gudjonsson, 2011). Researchers have since replicated and extended this paradigm to assess a variety of additional variables that are associated with false confessions, including stress (Forrest, Wadkins, \& Miller, 2002), age (Redlich \& Goodman, 2003), and the severity of the consequences (Horselenberg et al., 2006).

At this time, there is no scientific evidence to support the diagnosticity of the Reid technique. In other words, there is no research to suggest that these interrogation techniques are capable of increasing true confessions, while reducing false confessions (Russano, Meissner, Narchet, \& Kassin, 2005). Russano and colleagues (2005) developed an experimental paradigm to examine the diagnosticity of psychology-based interrogation practices. In this paradigm, participants were paired with a confederate for a problem-solving task, and were instructed to work alone on some questions, and together on others. In the guilty condition, the confederate asked the participant for help on a problem that was supposed to be solved alone, inducing a violation of the experimental protocol. In the innocent condition, the confederate did not seek assistance. The researcher then accused the pair of cheating, and used either minimization techniques or no minimization techniques to convince the participant to sign a confession. In the original study, results demonstrated that the confession rate was higher when minimization was used than when it was not. Importantly, however, minimization reduced diagnosticity by increasing, not only the rate of true confessions, but the rate of false confessions as well 
(Russano et al., 2005). Additional iterations of the Russano et al. (2005) paradigm have evaluated a number of factors that contribute to false confessions, including the influence of investigator bias (Narchet, Meissner, \& Russano, 2011), the impact of harsher consequences (Horgan, Russano, Meissner, \& Evans, 2012), and the diagnosticity of information-gathering interrogation approaches (Meissner, Russano, Rigoni, \& Horgan, 2011). Together, these results demonstrate that, although Reid interrogation techniques are successful in capturing true culprits, they simultaneously put innocent suspects at risk to falsely confess.

\section{The False Evidence Ploy}

Embedded within the Reid technique, and the maximization tactic, in particular, is the routine use of deception and the presentation of false evidence (Gohara, 2006). Referred to as the false evidence ploy, police may bolster an accusation and overcome a suspect's denial by presenting allegedly incriminating evidence, and suggesting that this incriminating evidence is sufficient to obtain a conviction - even if such evidence is fabricated or nonexistent (Kassin et al., 2010). For example, an interrogator may present fake eyewitness testimony, fingerprints that were not actually found, or fabricated polygraph results (Kassin et al., 2010).

Interrogators are permitted by law to lie about the presence of incriminating evidence, and the presentation of false evidence during an interrogation is generally accepted by courts and judges (Gohara, 2006). Kassin and colleagues (2007) found that, in a survey of 631 police interrogators, $92 \%$ admitted to using the false evidence ploy to elicit a confession. While Inbau and colleagues (2001) maintain that the false evidence ploy is diagnostic, research in this area has consistently demonstrated that false evidence ploys can, and do, lead to false confessions and wrongful convictions (see Stewart, Woody \& Pulos, 2018 for meta-analysis). In fact, false 
evidence is implicated in the vast majority of documented false confession cases (Kassin et al., 2010).

The false confession literature suggests that there are two mechanisms by which an innocent suspect might confess when confronted with false evidence (Perillo \& Kassin, 2010). First, the evidence may serve to convince an innocent suspect, regardless of their true culpability, that the police have a strong and compelling case against them, and they may confess as an act of behaviour compliance (i.e., a compliant false confession; Perillo \& Kassin, 2010). Specifically, when a suspect is confronted with seemingly incontrovertible evidence of their guilt, they may conclude that they are likely to be convicted in court (Gohara, 2006). In feeling a sense of hopelessness regarding their ability to discredit the evidence, many suspects capitulate when they believe that there is strong evidence against them (Moston, Stephenson \& Williamson, 1992). In self-report studies, real suspects stated that the reason they falsely confessed was because they perceived themselves to be trapped by the weight of the alleged evidence against them (Moston, Stephenson \& Williamson, 1992). Therefore, the use of false evidence ploys is cited as being helpful in convincing the suspect that their refusal to confess is futile (Gohara, 2006).

Alternatively, the presentation of false evidence may be powerful enough to lead suspects to doubt their own innocence and internalize guilt, such that they eventually come to believe that they may have committed the crime (i.e., an internalized false confession; Perillo \& Kassin, 2010). For some individuals, the presentation of false evidence may erode their confidence in their innocence, create a sense of confusion and a heightened state of suggestibility, and lead them to distrust their own recollections (Ofshe, 1989). Research has shown that post-event information can lead people to recall events differently from the way they actually occurred, or 
even to recall events that never occurred at all (Sacchi, Agnoli, \& Loftus, 2007). The same evidence that can lead a suspect to conclude that they will certainly be perceived as guilty, and that their conviction is inevitable, can also sometimes convince an innocent suspect that they are, in fact, guilty (David \& O’Donohue, 2004).

False Photograph and Video Evidence. As advanced image-editing software has become widely available, police are now able to present suspects with doctored photograph or video evidence (Sacchi, Agnoli, \& Loftus, 2007). For example, police may present an image or video that allegedly shows the suspect at the crime scene. Research suggests that the presentation of photograph evidence is powerful insofar as individuals tend to have a pervasive faith in the objectivity of photographs, such that they inherently, and blindly, believe their credibility (Garry \& Wade, 2005). Research has demonstrated that suspects perceive doctored images as highly compelling and credible evidence that the suggested event occurred (Nash, Wade \& Brewer, 2009) and that memory distortions can occur when mental images of a fictional event are mistaken for real experiences (Johnson, Foley, Suengas, \& Raye, 1988). Moreover, research suggests that suspects are unlikely to resist or challenge the accuracy of a photograph, and may even search their memory for event-consistent information (Wade et al., 2002). Feeding suspects photograph or video information can transform their beliefs, and cause them to distrust their memory (i.e.. memory distrust syndrome), encouraging them to turn to external sources (i.e., the alleged evidence) to infer whether the event happened (Nash \& Wade, 2009).

Prior research has examined the impact of false photograph and video evidence in manipulating distant autobiographical memories, and recollections of public events. Wade and colleagues (2002) exposed participants to a false childhood event via a doctored photograph 
which depicted each participant on a hot air balloon as a child. Over three interview sessions, half of the participants created false memories of this childhood experience. Similarly, Sacchi, Agnoli and Loftus (2007) exposed participants to photographs of significant public events, including a major peace demonstration that took place in Rome. Some of the participants viewed doctored photos of the demonstration, which depicted the event as more violent than it really was. Results demonstrated that participants exposed to the doctored photo recalled the demonstration as being more violent. Together, these studies demonstrate that false photograph evidence can be powerfully suggestive, and can alter individuals' beliefs and recollections of events.

False Physical Evidence. Additionally, police may present false physical evidence in the form of scientific evidence or technical evidence to convince a suspect that there is concrete evidence that connects them to the crime (Woody \& Forrest, 2009). For example, police may present a suspect with fingerprint records, polygraph results, medical tests, or blood spatter analyses, suggesting that they have scientific proof of their involvement in the crime. Research suggests that physical evidence ploys are powerful in eliciting confession because the mere mention of a complex scientific or technological procedure carries the prestige and incomprehensibility of modern science (Imwinkelried, 1983). Ofshe and Leo (1997) posit that physical evidence may be the most coercive and deceptive due to the suspect's perception that this type of evidence is irrefutable, and the fact that the suspect may not have the adequate expertise to discredit the evidence. Because scientific evidence is difficult to counter, both guilty and innocent suspects will have a difficult time explaining away evidence that is allegedly derived from an established and objective technological source (Ofshe \& Leo, 1997). 
Redlich and Goodman (2003) used the ALT-key paradigm to examine the effects of physical evidence on false confessions. After being accused of clicking the ALT-key and crashing the computer, half of the participants were shown physical evidence in the form of a printout allegedly outlining the keys that the participants had clicked during the study, which included the ALT key. Results demonstrated that participants in the false physical evidence condition were more likely to falsely confess than those who were not shown false physical evidence. These results suggest that the presentation of physical evidence can be powerful in convincing an innocent individual to falsely confess.

False Eyewitness Testimony. Interrogators may also present false eyewitness testimony, whereby they tell the suspect that an eyewitness has made an incriminating statement about the suspect's involvement in the crime (Woody \& Forrest, 2009). Research suggests that suspects generally view eyewitness evidence to be less threatening than other forms of evidence, as a suspect can more easily counter a claim of eyewitness evidence by maintaining that the witness is mistaken or lying (Ofshe \& Leo, 1997). Whereas photograph evidence and scientific evidence are viewed as infallible and error-free, suspects can more easily deny the claim of eyewitness evidence and maintain their innocence (Ofshe \& Leo, 1997).

In Kassin and Kiechel's (1996) original computer crash study, they had a confederate, who was posing as a peer of the participant, tell the experimenter that they witnessed the participant hit the ALT-key in half of the sessions. Results demonstrated that presentation of false eyewitness testimony increased false confessions from $48 \%$ to $94 \%$, compared to when no eyewitness testimony was included. These results suggest that eyewitness testimony can increase 
the risk of false confessions, and that a suspect may turn to a witness as a credible source of information when they are uncertain about the occurrence of an event.

Horselenberg, Merchelbach, and Josephs (2003) modified the computer crash paradigm in order to increase its plausibility and ecological validity. First, the experimenter acted as the eyewitness, rather than a non-involved independent peer, therefore more closely resembling an authoritative figure, such as an interrogator, who possesses privileged knowledge and can claim to have incriminating evidence. Additionally, in order to parallel the consequences of confessing in a real-life interrogation, the researchers included a negative consequence for falsely confessing, such that participants were told that those who do not confess to crashing the computer will received $\$ 10$, whereas those who do confess will only receive $\$ 2$. In spite of this cost, results demonstrated that, when presented with eyewitness testimony, $82 \%$ of the participants falsely confessed to crashing the computer. These results demonstrated that the mere presence of a witness who claims to have seen the act may be enough for many to falsely confess (Horselenberg et al., 2003).

\section{The Bluff Ploy}

A popular alternative to the false evidence ploy is the bluff ploy, whereby interrogators claim to have evidence, without physically presenting the evidence or asserting that this evidence necessarily implicates the suspect (Perillo \& Kassin, 2011). Examples of this technique include stating that a witness was present and will be interviewed, or that biological evidence was collected and will be sent to a laboratory for testing (Perillo \& Kassin, 2011). The bluff ploy presents the suspect with the plausible probability of the existence of evidence that implicates 
them - a prospect which is particularly important for an innocent suspect (Perillo \& Kassin, 2011).

Legal scholars suggest that, in theory, the bluff ploy should produce diagnostic outcomes, as true perpetrators will fear the inevitability of detection and will succumb to confessing, whereas innocent suspects will not feel similarly threatened and will not confess under these circumstances (Kassin, 2014). However, research has demonstrated that innocent suspects are also vulnerable to the bluff ploy, albeit for different reasons (Perillo \& Kassin, 2011). For innocent suspects, the threat of proof implied by the bluff represents a promise of future exoneration, which paradoxically makes it more appealing to confess (Kassin, 2005). Referred to as the phenomenology of innocence hypothesis, innocent suspects may believe that their confession will necessitate a future test of the evidence, which will ultimately prove their innocence (Perillo \& Kassin, 2011). Innocent suspects may opt to confess out of a misplaced confidence that their confession will be later disproved by exculpatory evidence (Perillo \& Kassin, 2010). Unfortunately, however, some innocent suspects may be naïve to the fact that their confession, regardless of its veracity, can override any alleged evidence, and that the confession alone will be enough to convict them (Forrest et al., 2012).

The literature regarding the differential effect of the false evidence ploy and the bluff ploy is mixed. Torkildson and Kassin (2008) used the forbidden key paradigm and found that the presentation of false eyewitness testimony increased false confession rates from $27 \%$ to $79 \%$. In the bluff condition, where participants were told that their keystrokes were being recorded and would be checked the following day, the false confession rate similarly increased to $87 \%$. Importantly, participants explained that the bluff implied a future promise of exoneration that 
made it easier to confess. This result was replicated by Perillo and Kassin (2011), who also used the forbidden key paradigm to explore the impact of the bluff ploy on false confessions. In the false evidence condition, a confederate claimed to have seen the participant strike the forbidden key. In the bluff condition, the researchers claimed that a device recorded the participant's keystrokes, but that this record was password-protected and would be checked at a later date. Results demonstrated that the false evidence ploy and the bluff ploy both increased false confession rates, in comparison to the control, but were not significantly related to high rates of internalization. Together, these results suggest that the bluff ploy is just as powerful as the false evidence ploy in eliciting false confessions. Moreover, these results suggest that the bluff ploy may put innocent suspects at risk for falsely confessing, as an act of behaviour compliance, rather than by altering beliefs in culpability.

Perillo and Kassin (2011) extended these findings, using Russano and colleagues' (2005) cheating paradigm to manipulate guilt and innocence and to compare control and bluff conditions. Experimenters claimed that a hidden camera had recorded the participants' behaviour and that this video could be checked at a later date. Results of the study demonstrated that the confession rate increased from 0 to $50 \%$ in the innocent condition when the bluff ploy was used. Importantly, these participants cited the bluff as a motivation to confess, believing that alleged evidence would be tested in the future, and would ultimately exonerate them. Instead of waiting for the video evidence to be retrieved, these participants confessed with the expectation that they would later be found innocent. Thus, participants in the bluff condition signed the confession, not as a result of internalization, but rather as an act of compliance stemming from the expectation that their innocence would be borne out by exculpatory evidence (Perillo \& Kassin, 2010). These 
results suggest that the bluff ploy may not a diagnostic interrogation tactic insofar as it provides innocent suspects with an incentive to confess.

In a study by Nash and Wade (2009), experimenters directly compared the false evidence ploy to the bluff ploy. Participants completed a computerized gambling task, and experimenters accused participants of taking money when they were supposed to return it. Half of the participants were exposed to a doctored video that depicted them committing the act (the seevideo group), and the other half were simply told that incriminating video evidence existed (the told-video group). Results demonstrated that the see-video subjects were more likely to confess and to internalize guilt than the told-video subjects. These results demonstrate that the presentation of false video evidence is more convincing than merely being told of its existence. Moreover, these results suggest that the false evidence ploy may promote internalization to a greater extent than the bluff ploy. Nash and Wade (2009) posit that the false evidence ploy may be more powerful insofar as showing suspects a piece of evidence will challenge their beliefs about the accuracy of their memory and will also provide an external source that they can use to infer that the event occurred.

Wilford and Wells (2018) conducted a study examining the effects of the bluff ploy on guilty and innocent participants, and used the cheating paradigm to manipulate guilt and innocence. Half of the participants were told that a video camera recorded their behaviour during the experiment, and could reveal whether cheating occurred. Consistent with the phenomenology of innocence hypothesis, innocent participants in the bluff condition viewed the chance of being charged with cheating as lower than innocent participants who did not hear the bluff. On the other hand, guilty participants expressed that the bluff made them feel trapped into confessing. 
The results of this study suggest that innocent individuals may view the bluff as a positive, insofar as it represents evidence that will ultimately exonerate them, whereas guilty individuals view the bluff as evidence supporting their guilt (Wilford \& Wells, 2018).

Therefore, research has demonstrated that the false evidence ploy and the bluff ploy are both effective in eliciting false confessions, albeit through different mechanisms. Perillo and Kassin (2011) referred to false evidence as "the most controversial tactic permissible within [the Reid technique of interrogation]" (p. 327). Interestingly, the bluff ploy does not receive the same negative attention or concern from the legal community, insofar as it does not involve the direct presentation of fabricated evidence. It is important to note, however, that the bluff ploy does not insulate innocent suspects from the risk of false confession - either in absolute terms, or in comparison to the false evidence ploy — such that innocent suspects may falsely confess out of an expectation of future exoneration (Perillo \& Kassin, 2010). When interrogators use the false evidence ploy, suspects may become convinced that the police have a compelling case against them, viewing confessing as their only option; alternatively, suspects may come to believe that they committed the act at hand. Suspects exposed to the bluff ploy, on the other hand, may use the alleged evidence to extricate themselves from the situation as an act of behavioural compliance, without altering beliefs in culpability.

Research on the power of the bluff ploy in eliciting false confessions is inconsistent. Specifically, previous research on the differential impact of the false evidence ploy and the bluff ploy is mixed, and the underlying mechanisms at play, particularly for innocent suspects, have yet to be explicitly examined.

\section{Summary}


At this time, it is important to address the issues within our criminal justice system that are putting innocent people at risk to falsely confess. Through research on police deception and the use of false evidence, we can identify the factors that are increasing innocent defendants' risk to falsely confess. While the legal community maintains that using deceitful tactics, such as a false evidence, are a valuable and necessary tool for eliciting confessions, empirical research has consistently demonstrated that these tools are not diagnostic, insofar as they put innocent defendants are risk to falsely confess. The present study extends the false evidence literature, and examines the role of the false evidence ploy and the bluff ploy in false confessions. This empirical research can help inform meaningful and substantial policy and system-wide changes in the hopes of preventing future false confessions and wrongful convictions.

\section{Present Study and Hypotheses}

At present, interrogators can legally a) produce and present fake or doctored evidence, and b) tell suspects that incriminating evidence exists, even though it does not (Kassin, 2017; Inbau et al., 2001). Field research (e.g., Firstman \& Salpeter, 2008) and experimental research (e.g., Nash \& Wade, 2009; Perillo \& Kassin, 2010) on the impact of false evidence has consistently demonstrated that both the false evidence ploy and the bluff ploy increase the rate of false confessions, and in turn, wrongful convictions. Although there are several studies that have examined the impact of false evidence on false confessions rates (see Stewart, Woody \& Pulos, 2018 for meta-analysis), the methodologies of these studies were limited to testing the effects of the false evidence ploy against a control group (i.e., one which lacked false evidence) in eliciting false confessions, and thus there is little known about whether certain variants of false evidence are differentially powerful in eliciting false confessions. The present study was the first to 
directly compare different variants of false evidence, and to explicitly examine whether these variants differentially affect false confession rates. The present study examined the following: a) the effect of three different variants of false evidence (photograph, eyewitness, physical) on false confessions and internalization, and b) the differential effect of the false evidence ploy and the bluff ploy on false confessions and internalization.

A subsidiary aim of the present study was to explore to what extent individual difference variables contribute to false confessions. Previous research has demonstrated that high scores on the Gudjonsson Compliance Scale (Gudjonsson, 1989) are related to false confessions. For example, research has shown that prison inmates who claimed to have falsely confessed had significantly higher GCS scores than controls (Sigurdsson \& Gudjonsson, 1996). Additionally, research has demonstrated a relationship between fantasy proneness and false confessions. For example, Horselenberg and colleagues (2006) accused participants of crashing the computer, and found that participants who falsely confessed to this act scored higher on fantasy proneness than non-confessors (with means of 7.8 and 5.8, respectively).

The review of the literature on the impact of the false evidence and the bluff ploy on false confessions led to the following hypotheses:

1. A main effect of evidence variant on false confessions, such that participants in the photograph evidence condition would be more likely to falsely confess than participants in the physical evidence condition and eyewitness testimony condition; and participants in the physical evidence condition would be more likely to falsely confess than participants in the eyewitness testimony condition. 
2. No main effect of evidence ploy on false confessions, such that there would be no significant differences in false confession rates between participants in the false evidence ploy condition and participants in the bluff ploy condition.

3. A main effect of evidence variant on internalization, such that participants in the photograph evidence condition would have higher rates of internalization than participants in the physical evidence condition and eyewitness testimony condition; and participants in the physical evidence condition would have higher rates of internalization than participants in the eyewitness evidence condition.

4. A main effect of evidence ploy on internalization, such that participants in the false evidence ploy would have higher rates of internalization than participants in the bluff ploy condition.

\section{Chapter II: Method}

\section{Participants}

A total of 230 undergraduate students from Ryerson University were recruited through Ryerson's psychological research recruitment system (SONA). Participants were compensated $1 \%$ toward their introductory Psychology course grade for their participation. During debriefing, participants were asked whether they were skeptical of the true nature of the study. If participants indicated that they were aware of the deception present in the study and provided a specific reason (e.g., the personality questionnaires measuring compliance sparked doubt, they learned about deception in a recent lecture, they had participated in a similar study prior), their data was excluded from analyses. Using this criterion, 12 participants were excluded. As a result, the final sample included 218 participants ( $87.6 \%$ females). Ages ranged from 17 to 54 , with a mean of 
$20.17(S D=4.92)$. The sample was predominantly White $(30.7 \%)$, with $34(15.6 \%)$ identifying as Chinese, 32 (14.7\%) identifying as South Asian, 23 (10.6) identifying as Filipino, 10 (4.6\%) identifying as Black, and the rest identifying as Korean, Arab, Southeast Asian, West Asian, or 'Other.'

\section{Design}

The present study was a 2 (evidence ploy: false evidence ploy vs. bluff ploy) x 3 (evidence variant: eyewitness testimony, physical evidence, photographic evidence) betweensubjects factorial design with a dichotomous dependent variable. Participants were randomly assigned to one of the following six conditions using an online random number generator: 1) false eyewitness testimony $(\mathrm{N}=37) ; 2)$ false physical evidence $(\mathrm{N}=36) ; 3)$ false photograph evidence $(\mathrm{N}=37)$; 4) bluffed eyewitness testimony $(\mathrm{N}=36) ; 5)$ bluffed physical evidence $(\mathrm{N}=$ 37); or 6) bluffed photograph evidence $(\mathrm{N}=35)$.

\section{Materials}

Gudjonsson Compliance Scale (GCS; Gudjonsson, 1989). The GCS includes 20 truefalse statements that assesses participants' susceptibility to complying with requests and obeying instructions when under pressure (Gudjonsson, 1989). The statements assess uneasiness or fear of authority figures and avoidance of conflict and confrontation (e.g., "I tend to become easily alarmed and frightened when I am in the company of people in authority") and the eagerness to please others and to do what is expected of them (e.g., "I try have to do what is expected of me"; see Appendix A). The scale is scored by summing the "true" answers, with higher scores indicating higher levels of compliance. Items 17, 18, and 19 are reverse coded. This scale 
possesses a reliability coefficient of .88 (Gudjonsson, 1989). Both the current study $(\alpha=.69)$ and Gudjonnson (1989; $\alpha=.71)$ reported good internal consistency.

\section{The Creative Experiences Questionnaire (CEQ; Merckelbach, Horselenberg, \&}

Muris, 2001). The CEQ is a 25 -item yes/no index that assesses fantasy proneness (e.g., "in general, I spend at least half of the day fantasizing or daydreaming"; "my fantasies are so vivid they are like a good movie" (see Appendix B). The questionnaire is scored by summing the "yes" answers, with higher scores indicating higher fantasy proneness. Both the current study $(\alpha=.79)$ and Merckelbach and colleagues $(2001 ; \alpha=.72)$ reported good internal consistency.

Demographic Questionnaire. Participants completed a demographic questionnaire which included questions about their gender, age, and ethnicity (see Appendix C).

Logical Reasoning Task. Participants completed 17 logical reasoning questions on Qualtrics. All of the questions were multiple choice (see Appendix D).

Confession Statement. False confessions were measured by asking participants to sign a handwritten confession statement spontaneously written up by the experimenter that stated the following: "Participant hit the space bar and saw the answer. Their data cannot be used" (see Appendix E).

Follow-Up Questions. Prior to the official debriefing, participants were asked four follow-up questions about their decision to confess or not (see Appendix F). Although these questions were included to gain a more thorough and nuanced understanding of participants' confession decision, the primary goal was to measure participants' internalization. Internalization was measured by asking participants why they admitted to clicking the space Bar and whether 
they came to believe that they had clicked the space bar. Participants' responses were recorded verbatim using an audio recorder and were later transcribed.

\section{Procedure}

The present study was approved by the Research Ethics Board at Ryerson University. Participants were greeted by the experimenter in the laboratory waiting room and brought into a testing room. The experimenter explained that the goal of the study is to investigate how personality characteristics relate to performance on a logical reasoning task. The experimenter asked participants to read over and sign the informed consent form (see Appendix G) .

Participants completed the Gudjonsson Compliance Questionnaire, the Creative Experiences Questionnaire, and a demographic questionnaire on Qualtrics. Participants were then given instructions about the logical reasoning task. Participants were warned not to press the space bar, as doing so would cause the answer to the logical reasoning question to appear on the screen, thus violating the integrity of the experimental results. After ensuring that participants understood this rule, the experimenter directed the participant to start the logical reasoning task on the computer.

After participants completed the logical reasoning task, the experimenter entered the room and asked the participant if they clicked the space bar and saw the answer at any point during the experiment. When participants denied this allegation, the experimenter exited the room for two minutes. The experimenter then re-entered the room, and presented the participant with false evidence in one of six forms. In the false photograph evidence condition, the experimenter showed participants a photograph on a cellphone. The photograph ostensibly shows the participant from behind, seated at the lap top computer, with the answer to the logical 
reasoning task being displayed on the computer screen (implying that the participant clicked the forbidden space bar to reveal the answer on the screen; see Appendix H and I). The same photograph was shown to all participants in this condition. This photo was taken beforehand and was not actually taken of the participant. The room was arranged such that certain objects (e.g., a lit lamp, and a hand sanitizer on the desk) appear in the photograph, reinforcing the idea that the photo was taken of them. In the false physical evidence condition, the experimenter presented participants with a printout of a keyboard tracking report, indicating that the participant pressed the space bar during the duration of the experiment (see Appendix $\mathrm{J}$ and $\mathrm{K}$ ). In the false eyewitness testimony condition, the experimenter provided the participant with a research assistant note that indicated that the research assistant saw the participant click the space bar from the other room via a double-sided mirror (see Appendix L and M).

In the bluffed photograph evidence condition, the experimenter explained that there was a camera in the room and that it could be checked to see whether or not the participant clicked the space bar at a later date (see Appendix N). In the bluffed physical evidence condition, the experimenter explained that the laptop computer is connected to a keyboard tracker, and that it could be checked later to determine with certainty whether the participant clicked the space bar (see Appendix O). In the bluffed eyewitness testimony condition, the experimenter explained that the research assistant was responsible for watching and taking notes during the experiment, and that they could be asked later if they noted down that whether participant click the space bar (see Appendix P).

After being presented with the false or bluffed evidence, participants were asked to sign a confession statement indicating that they clicked the space bar, and that their data could not be 
used. On the spot, the experimenter wrote a confession statement that stated the following: "Participant clicked the space bar and saw the answer. His/her data cannot be used." The experimenter presented the statement to the participant with a request to read and to sign it. If the participant declined to sign the statement, the experimenter asked them one more time. The decision to sign or not sign a confession served as the primary dependent measure.

Before being explicitly debriefed, the experimenter asked participants a set of follow-up questions that measured internalization and provided insight into participants' confession decision. Answers were audio recorded and transcribed. Participants were then thoroughly debriefed about the true nature of the study (see Appendix Q). The experimenter explained why it is sometimes necessary to use deception in social science research. Participants were given the opportunity to ask any questions that they had, and were asked to refrain from discussing the details of the study with other potential participants in order to maintain the integrity of the experimental design. Participants were reassured that they will receive course credit for their participation, that their data will, in fact, be used, and that they are not in any trouble. Participants were then asked to reconfirm their consent to the use of their data by signing a reconsent form (see Appendix R).

\section{Chapter III: Results}

\section{False Confessions}

False confessions were coded as a dichotomous variable: $0=$ participant did not sign the confession statement; 1 = participant signed the confession statement. Of the 218 participants, 86 participants (39.4\%), all of whom were innocent, falsely confessed. Specifically, these participants signed the confession statement, admitting to pressing the space Bar and seeing the 
answer. One hundred and thirty-two participants (60.6\%) did not falsely confess, such that they did not agree to sign the confession statement after being prompted twice.

\section{Hypothesis \#1: Evidence Variant and False Confessions}

I hypothesized a main effect of evidence variant on false confessions, such that participants in the photograph evidence condition would be more likely to falsely confess than participants in the physical evidence condition and eyewitness testimony condition; and participants in the physical evidence condition would be more likely to falsely confess than participants in the eyewitness testimony condition. A binary logistic regression confirmed this hypothesis, such that participants in the photograph evidence condition (56.9\%) were significantly more likely to falsely confess than participants in the physical evidence condition (42.5\%), and participants in the eyewitness testimony condition (19.2\%), $B=1.51, S E=.305, p<$. $001, \operatorname{Exp}(B)=3.16,95 \% \mathrm{CI}[1.740,5.741]$. Further analyses demonstrated that participants in the physical evidence condition were significantly more likely to falsely confess than those in the eyewitness testimony condition, $B=1.135, S E=.380, p<.05, \operatorname{Exp}(B)=3.11,95 \%$ CI $[1.477,6.552]$. See Figure 1.

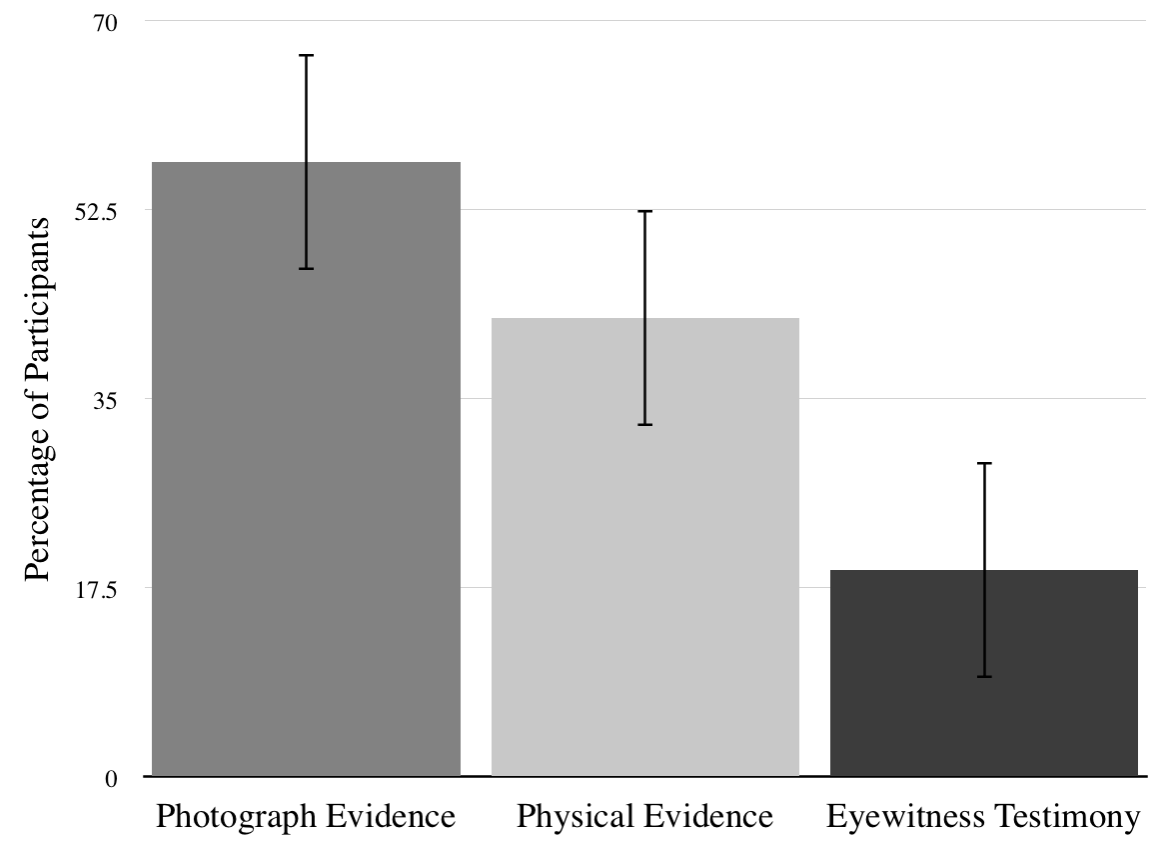

Figure 1. Percentage of false confessions by evidence variant, $p<.005$ 


\section{Hypothesis \#2: Evidence Ploy and False Confessions}

I hypothesized no main effect of evidence ploy on false confessions, such that there would be no significant difference in false confession rates between participants in the false evidence ploy condition and participants in the bluff ploy condition. However, results of a binary logistic regression demonstrated otherwise, such that participants in the false evidence ploy condition $(58.2 \%)$ were significantly more likely to falsely confess than participants in the bluff ploy condition $(20.4 \%), B=1.694, S E=.31, p<.001, \operatorname{Exp}(\mathrm{B})=5.44,95 \% \mathrm{CI}[2.978,9.933]$.

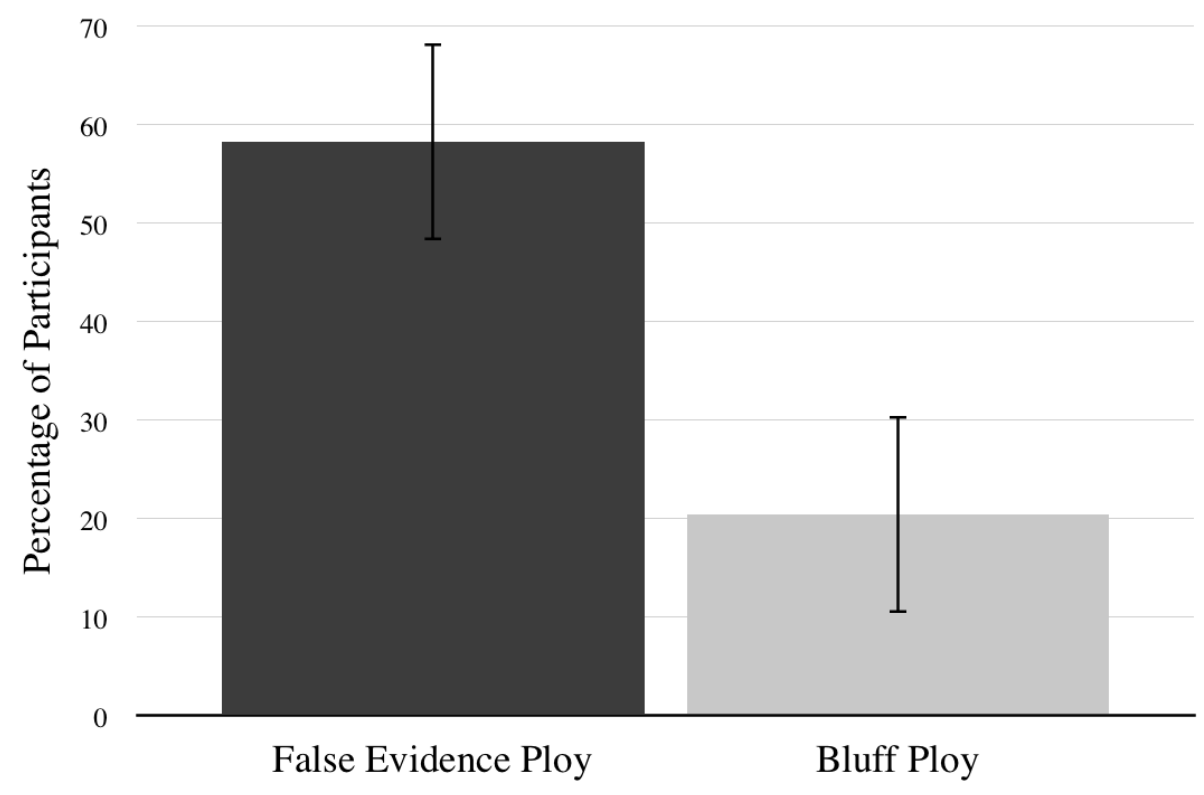

Figure 2. Percentage of false confessions by evidence ploy, $p<.001$

\section{Internalization}

Internalization was coded using Redlich and Goodman's (2003) trichotomous coding scheme: $0=$ no internalization (e.g., 'I was accused of clicking the space bar, but I know that I did not'); 1 = partial internalization (e.g., 'I don't know, I may have accidentally clicked the space bar'); 2 = total internalization (e.g., 'I pressed the space bar and saw the answer'). Of the 
218 participants, 33 participants (15.1\%) fully internalized guilt, 41 participants $(18.8 \%)$ partially internalized guilt, and 144 participants (66.1\%) did not internalize guilt.

Internalization and False Confessions. Using Redlich and Goodman's (2003) data analysis approach, the remaining internalization results were coded as a dichotomous variable, with 0 representing no internalization or partial internalization $(\mathrm{N}=185)$, and 1 representing full internalization $(\mathrm{N}=33)$. Among the 86 participants who falsely confessed, 33 participants $(38.3 \%)$ internalized guilt, and 53 participants $(61.7 \%)$ did not internalize guilt, $\chi^{2}(1)=59.68$, $p<.001$. More specifically, of the 33 participants who internalized guilt, 100\% falsely confessed, such that no participants internalized guilt and did not confess.

\section{Hypothesis \#3: Evidence Variant and Internalization}

I hypothesized a main effect of evidence variant on internalization, such that participants in the photograph evidence condition would have higher internalization rates than participants in the physical evidence condition and eyewitness testimony condition; and participants in the physical evidence condition would have higher internalization rates than participants in the eyewitness testimony condition. A chi-square analysis confirmed this hypothesis, such that $29.1 \%$ of participants $(21 / 72)$ in the false photograph evidence internalized guilt, $15.1 \%$ of participants (11/73) in the false physical evidence condition internalized guilt, and 1.4\% (1/73) of participants in the eyewitness testimony condition internalized guilt, $\chi^{2}(2)=21.81, p<.001$. Of the participants who internalized guilt and falsely confessed $(\mathrm{N}=33), 1$ participant $(3 \%)$ was in the eyewitness testimony condition, 11 participants $(33 \%)$ were in the physical evidence condition, and 21 participants $(66 \%)$ were in the photograph evidence condition, $\chi^{2}(2)=21.8$, $p<.001$. 
Table 1 Evidence variant and percentage of false confessions and internalization

\begin{tabular}{lll}
\hline Evidence variant & Total false confessions (\%) & Internalized false confessions (\%) \\
\hline Eyewitness testimony & $19.2 \%$ & $3.3 \%$ \\
Physical evidence & $42.5 \%$ & $33.3 \%$ \\
Photograph evidence & $56.9 \%$ & $63.3 \%$ \\
\hline
\end{tabular}

\section{Hypothesis \#4: Evidence Ploy and Internalization}

I hypothesized a main effect of evidence ploy on internalization, such that participants in the false evidence condition would have higher rates of internalization than participants in the bluff ploy condition. A chi-square analysis confirmed this hypothesis, such that participants in the false evidence condition (28.1\%) were significantly more likely to internalize guilt than participants in the bluff ploy condition $(1.8 \%), \chi^{2}(2)=29.41, p<.001$. Of the participants who internalized guilt and falsely confessed $(\mathrm{N}=33), 31$ participants $(94 \%)$ were in the false evidence condition, and 2 participants $(6 \%)$ were the bluff ploy condition, and $\chi^{2}(2)=29.41, p<$. 001.

Table 2 Evidence ploy and percentages of false confessions and internalization

\begin{tabular}{lll}
\hline Evidence ploy & Total confessions (\%) & Internalized false confessions \\
\hline Bluff ploy & $20.4 \%$ & $6 \%$ \\
False evidence ploy & $58.2 \%$ & $94 \%$ \\
\hline
\end{tabular}

\section{Personality Factors}

Gudjonsson Compliance Scale and False Confessions. Total scores on the Gudjonsson Compliance Scale ranged from from 0 to $20(M=11.23, S D=3.46)$. A point-biserial correlation was conducted to examine the relationship between participants' scores on the GCS (a continuous variable) and whether they falsely confessed (a dichotomous variable). This analysis 
revealed that participants who scored high on the Gudjonsson Compliance Scale (i.e., indicating a more compliant personality) were more likely to falsely confess, $r \mathrm{pb}=.136, p<.05$.

Creative Experiences Questionnaire and False Confessions. Total scores on the Creative Experiences Questionnaire ranged from 0 to $23(M=10.36, S D=4.76)$. A point-biserial correlation was conducted to examine the relationship between participants' score on the CEQ (a continuous variable) and whether they falsely confessed (a dichotomous variable). This analysis revealed that participants who scored higher on the Creative Experiences Questionnaire (i.e., who demonstrate more fantasy proneness) were not more likely to falsely confess, $r \mathrm{pb}=.059, p=.386$

\section{Chapter IV: Discussion}

False confessions elicited by deceptive police interrogation tactics are a leading contributing factor to wrongful convictions (The Innocence Project, 2019). In particular, empirical research and case studies have demonstrated that the use of the false evidence ploy and the bluff ploy during police interrogations both increase the likelihood that an innocent person will falsely confess (e.g., Davis \& O’Donohue, 2004; The Innocence Project, 2019; Kassin \& Kiechel, 1996; Perillo \& Kassin, 2010). The present study examined the effect of different variants of false evidence, as well as the differential effect of the false evidence ploy and the bluff ploy, on false confessions and internalization.

The primary hypothesis of the present study, that false photograph evidence would be the most powerful in eliciting false confessions, followed by the false physical evidence, and false eyewitness testimony, was supported. Results also demonstrated that, contrary to our hypothesis, participants were more likely to falsely confess in the false evidence condition, compared to the 
bluff ploy condition. Moreover, results demonstrated that participants were more likely to internalize guilt in the photograph evidence condition, compared to the physical evidence condition and the eyewitness testimony condition. Participants were also more likely to internalize guilt in the false evidence condition, compared to the bluff ploy condition.

\section{False Confessions}

Despite being innocent, $39.4 \%$ of participants falsely confessed to clicking the space Bar, and seeing the answer to the logical reasoning task. This false confession rate is consistent with results from a recent meta-analysis that reported that, across 24 false confession studies using a forbidden act paradigm, the average false confession rate was $47 \%$ (see Stewart, Woody, \& Pulos, 2018 for meta-analysis). Previous experimental studies using a forbidden key paradigm have demonstrated false confession rates ranging from 19\% (Newring \& O’Donohue, 2008), to 27\% (Blair, 2007), to $47 \%$ (Klaver, Lee, \& Rose, 2008), to 58\% (Horselenberg et al., 2006), and 77\% (Perillo \& Kassin, 2010).

\section{Internalization}

Of the 218 participants, 33 participants (15.1\%) fully internalized guilt, and 185 participants (84.9\%) did not internalize guilt. Importantly, of the 86 participants who falsely confessed, 33 internalized guilt, and 53 did not internalize guilt. Therefore, 33 participants made an internalized false confession, whereas 53 participants made a compliant false confession. This finding is consistent with extant literature regarding the various types of false confessions and the mechanisms through which false evidence can elicit false confessions (Perillo \& Kassin, 2010). Specifically, research suggests that false evidence may influence an innocent suspect's decision to confess by a) convincing them that the evidence against them is strong and that denial 
is futile (i.e., a compliant false confession), or b) by creating a state of confusion such that they come to believe they committed the crime (i.e., an internalized false confession; Perillo \& Kassin, 2010). In the present study, some participants made a compliant false confession, insofar as they confessed due to the weight of the evidence or the stress of the accusation, whereas other participants made an internalized false confession, such that they internalized guilt and came to question whether they clicked the space bar.

\section{Different Variants of False Evidence}

Our hypothesis that participants in the photograph evidence condition would be most likely to false confess, followed by participants in the physical evidence condition, and participants in the eyewitness testimony condition, was supported. In the present study, $56.9 \%$ of participants in the false photograph evidence condition falsely confessed. Of the participants who falsely confessed in this condition, $63.3 \%$ internalized guilt. This finding is consistent with previous research that suggests that photograph evidence has the potential to cultivate false memories of events or experiences that never occurred (Wade \& Garry, 2005). Research suggests that photograph evidence is powerful as individuals have a blind faith in the objectivity of photographs, and view photographs as being a credible source of information (Wade \& Garry, 2005). Because individuals inherently believe in the objectivity and reliability of photographs, they are likely to take photographic evidence at face value. Therefore, the high false confession rates and the high internalization rates in the false photograph evidence condition likely go handin-hand, such that participants in this condition were more likely to internalize guilt, and were thus more willing to admit guilt. 
Additionally, research has shown that physical evidence, particularly technical or scientific evidence, can be powerful in eliciting false confessions (Gohara, 2006). Our results demonstrated that participants were less likely to falsely confess in the false physical evidence condition than in the photograph evidence condition, but more likely to confess than those in the eyewitness testimony condition. Specifically, $42.5 \%$ of participants in the physical evidence condition confessed, and 33.3\% internalized guilt. Therefore, the majority of the false confessors in the physical evidence condition made a compliant false confession, rather than an internalized false confession. This finding is consistent with previous literature on the power of scientific and technical evidence and the mechanisms through which they may elicit false confessions. Imwinkelried (1983) suggests that our society has a misplaced fascination with science and technology, such that individuals too quickly and easily accept scientific knowledge as fact, and view scientific and technological data as infallible and irrefutable (Gohara, 2006). Therefore, false evidence ploys that are based on scientific processes or technical equipment are influential because of the association with the prestige and incomprehensibility of modern science (Imwinkelried, 1983). As a result, suspects may perceive this evidence to be powerful and incontrovertible, and may consequently confess due to the weight and strength of the evidence against them.

Moreover, because suspects oftentimes do not have the adequate expertise to discredit complex scientific jargon or highly specialized technological equipment, it may be difficult for suspects to refute evidence that is produced by these technologies (Gohara, 2006). In the present study, participants were shown a keyboard tracking report, that included a series of numbers, symbols, and complex sequences. Because most participants are not familiar with how keyboard 
tracking devices work, it may have been difficult for participants to disprove the keyboard tracking evidence, which they were told was derived from an established and objective technological source (Gohara, 2006). For that reason, participants may have confessed because they had no valid excuse or explanation to discount the evidence.

The eyewitness testimony condition had the lowest false confession and internalization rates, with $19.2 \%$ of participants in the eyewitness testimony condition falsely confessing, and $3.3 \%$ of these false confessors internalizing guilt. This result is consistent with previous research that suggests that, although photograph evidence and physical evidence are viewed as being infallible and error-free, eyewitness testimony is significantly less threatening as suspects can discount a claim of an eyewitness by maintaining that the eyewitness is lying or not credible (Ofshe \& Leo, 1997). In the present study, participants were quick to discredit the eyewitness (i.e., the research assistant), making statements, such as: "I thought she saw wrong or maybe she couldn't see well through the mirror," "I thought the RA was just lying or something", or "My first thought was just 'she's wrong!"” Therefore, instead of accepting the research assistant's accusation at face value, as one may be willing to do with photograph evidence or technical documentation, participants discredited the research assistant's allegation and maintained their innocence. In effect, the eyewitness statement did not convince the participants that there was strong evidence of their culpability, nor did it lead participants to question their innocence.

\section{The False Evidence Ploy and The Bluff Ploy}

Prior research examining the differential effect of the false evidence ploy and the bluff ploy has been mixed. For example, Perillo and Kassin (2010) found that the bluff ploy increases false confessions at a comparable rate to the effect produced by false evidence, whereas Nash \& 
Wade (2009) found that participants who were physically shown evidence were more likely to falsely confess than those who were simply told that the evidence exists. Based on research on the phenomenology of innocence (e.g., Kassin, 2012; Perillo \& Kassin, 2010), I hypothesized that participants in the false evidence condition and participants in the bluff ploy condition would be equally likely to falsely confess. The results of the present study did not support this hypothesis, such that participants in the false evidence condition (58.2\%) were significantly more likely to falsely confess than those in the bluff ploy condition (20.4\%). Of the 33 participants who internalized guilt, 31 were in the false evidence condition, whereas only 2 were in the bluff ploy condition. Therefore, participants in the false evidence condition, who were physically confronted with evidence, were more likely to falsely confess, and to internalize guilt, than participants who were just told about the evidence. Although I can not determine causation, the high internalization rates in the false evidence condition may help explain the higher false confession rates. This result is consistent with prior research that suggests that 'seeing is believing,' such that participants who are physically presented with evidence are more likely to develop false memories and to internalize guilt, than participants who are merely told about the existence of evidence (McCabe \& Castel, 2008; Nash \& Wade, 2009; Perillo \& Kassin, 2010). Nash and Wade (2009) suggest that telling suspects about incriminating evidence may challenge their beliefs about the reliability of their memory, or may present the possibility for future exoneration, whereas physically showing evidence will both challenge a suspect's beliefs and memories and provide an external source that they can rely on to infer that the act occurred.

It is important to note that prior research examining the phenomenology of innocence suggests that the reason why the bluff ploy is powerful in eliciting confessions from innocent 
individuals is because the bluff represent a promise of future exoneration, which makes it easier for innocent individuals to confess (Perillo \& Kassin, 2011). When innocent suspects are told that evidence exists and that it may be uncovered at a later date, they may believe that their confession will necessitate a future test of the evidence, which will ultimately prove their innocence (Perillo \& Kassin, 2011). In doing so, however, innocent suspects may sign a confession statement, with the contingency that they be will exonerated later. Unlike some bluff ploys that explicitly mention that the alleged evidence may exculpate them (Perillo \& Kassin, 2011), participants in our study were not cued with the possibility that the evidence could demonstrate their innocence. Although participants were told that the evidence would be checked at a later date, there was no suggestion that this evidence could or would prove their innocence. Due to the ethical constrains of experimental protocol (i.e., particularly anonymity and confidentiality), and the confines of a university-run participation pool, it was not possible to include a promise of future exoneration into the experimental protocol, while maintaining believability. This lack of a promise of future exoneration may account for the discrepancy in false confessions between the false evidence condition and the bluff ploy condition. It is important to note that none of the participants in the sample mentioned that they did confessed based on a belief that the future examination of the evidence would demonstrate their innocence.

\section{Dispositional Factors}

In addition to the situational pressures inherent within a police interrogation, research suggests that there are a number of dispositional factors that increase the likelihood of false confessions. While not a primary focus of my study, I investigated whether two previously established dispositional risk factors, compliance and fantasy proneness, predicted participants' 
willingness to falsely confess. Previous research has demonstrated that individuals who score higher on compliance (e.g., Sigurdsson \& Gudjonsson, 1996), and individuals who score higher on fantasy proneness (e.g., Horselenberg, Merckelbach, \& Josephs, 2003) are more likely to falsely confess. In the current study, a point biserial correlation revealed that participants who scored higher in compliance were more likely to falsely confess; however, participants who scored higher in fantasy proneness were not more likely to falsely confess.

\section{Limitations and Future Directions}

Although the present study successfully captured important distinctions between different variants of false evidence, and between the false evidence ploy and the bluff ploy, there are a few limitations of the present study that are important to note. First, the present study used a laboratory paradigm using a student population that were accused of violating an experimental

protocol, and not defendants facing serious criminal charges and prison time. Although our study included a behavioural measure, the risks and punishments were far less serious for our participants than would be for real defendants. Accordingly, the length and setting of the interrogation, as well as the power dynamic between the participant and the experimenter, do not parallel an actual police interrogation. Due to ethical considerations regarding the stressful nature of the study, participants were relieved of the belief that they had done something wrong as soon as possible. As a result, participants could not be questioned for the length of an average interrogation, exposed to high levels of stress and harsh treatment, and or at risk of severe consequences or incarceration.

A second limitation of the present study is the fact that our script did not include the promise of future exoneration. Research on the phenomenology of innocence (e.g., Perillo \& 
Kassin, 2010) suggests that the bluff ploy is powerful in eliciting false confessions because of its implicit promise of future exoneration. Because of the confines of our study, our script did not allude to a future examination of the evidence that could exonerate the participant. This drawback of our study may account for the low false confession rates in the bluff ploy condition.

Additionally, all of the participants in our study were innocent of clicking the space bar and seeing the answer; therefore, it was not possible to elicit true confessions and to assess the diagnosticity of the false evidence ploy and the bluff ploy. Future research should manipulate guilt and innocence using Russano and colleague's (2005) cheating paradigm, to examine whether the effects of false evidence and the bluff ploy vary between guilty and innocent participants.

\section{Implications}

Today, false confessions are considered a leading contributing factor to wrongful convictions (The Innocence Project, 2019). Empirical data, along with examinations of wrongful conviction cases, has consistently demonstrated that interrogation practices involving the presentation of false evidence lead to false confessions (e.g., Kassin \& Kiechel, 1997; Nash \& Wade, 2009; Perillo \& Kassin, 2010; The Innocence Project, 2019). Despite increasing numbers of false confessions that have resulted from police deception, very few criminal justice reforms have been put in place, and the use of deception and false evidence is legally permissible and approved by courts (Gohara, 2006).

One safeguard that has been put in place is the standard of voluntariness, such that a judge, before admitting a confession into evidence, must determine whether the confession was made voluntarily and not via coercive methods (Woody \& Forrest, 2009). However, research has 
shown that interrogations that employ the false evidence ploy or the bluff ploy, whereby suspects are misled about incriminating evidence, are generally determined to be voluntary (Gohara, 2006). For example, confessions elicited through a police lying about the existence of an eyewitness or the fabrication of bloodstain evidence, have been deemed voluntary, and were admissible as evidence in court (Gohara, 2006). The present study demonstrated that the use of false evidence is inherently coercive, and that confessions made in light of false evidence should be re-evaluated in terms of their voluntariness. Specifically, the present study suggests that false photograph evidence is particularly powerful in eliciting false confessions, followed by false physical evidence, and false eyewitness testimony. The results of the present provide a basis for reconsidering the laws and guidelines that allow police to use trickery to obtain confessions insofar as they increase the likelihood that an innocent individual will falsely confess (Gohara, 2006).

More broadly, the legal system should aim to increase the diagnostic value of police interrogations, by reducing or circumscribing the use of false evidence ploys, particularly false photograph evidence, that induce innocent suspects, to falsely confess. It is worth taking a more careful look at the current laws and guidelines to determine whether there are systematic changes that could be made to reduce wrongful convictions. Moreover, we should be encouraging the use of investigative interviewing practices (i.e., the presumption of innocence, the emphasis on factfinding, and the use of open-ended question), such as the PEACE model, that have shown to improve diagnosticity and reduce wrongful convictions (Kassin, Appleby, \& Perillo 2010).

\section{Conclusion}


The present study investigated the effects of different forms of false evidence on false confessions, as well as the differential impact of the false evidence ploy and the bluff ploy, on false confessions. Our primary hypothesis was supported, such that the photograph evidence was the most powerful in eliciting false confessions, followed by the false physical evidence, and the false eyewitness testimony. I also found that, contrary to our hypothesis, the false evidence ploy was more powerful than the the bluff ploy in eliciting false confessions. Additionally, the present study demonstrated higher rates of internalization in the photograph evidence condition, compared to the physical evidence condition, and eyewitness testimony condition, as well as higher rates of internalization in the false evidence ploy condition, compared to the bluff ploy condition. Finally, the results of the present study suggest that participants who scored higher on compliance were more likely to falsely confess. 
Appendices

Appendix A

The Gudjonsson Compliance Scale

1. I give in easily to people when I am pressure

TRUE FALSE

2. I find it very difficult to tell people when I disagree with them

TRUE FALSE

3. People in authority make me feel uncomfortable and uneasy

TRUE FALSE

4. I tend to give in to people who insist that they are right

TRUE FALSE

5. I tend to become easily alarmed and frightened when I am in the

TRUE FALSE company of people of authority

6. I try very hard not to offend people in authority

TRUE FALSE

7. I would describe myself as a very obedient person

TRUE FALSE

8. I tend to go along with what people tell me even when I know that

TRUE

FALSE they are wrong

9. I believe in avoiding rather than facing demanding and frightening

TRUE

FALSE situations

10. I try to please others

TRUE FALSE

11. Disagreeing with people often takes more time than it is worth

TRUE

FALSE

12. I generally believe in doing as I am told

TRUE

FALSE

13. When I am uncertain about things I tend to accept what people tell

TRUE

FALSE me

14. I generally try to avoid confrontation with people

TRUE

FALSE

15. As a child I always did what my parents told me

TRUE FALSE

16. I try hard to do what is expected of me

TRUE FALSE

17. I am not too concerned about what people think of me

TRUE

FALSE

18. I strongly resist being pressured to do things I don't want to do

TRUE

FALSE

19. I would never go along with what people tell me in order to please

TRUE

FALSE them

20. When I was a child I sometimes took the blame for things I had

TRUE

FALSE not done 
Appendix B

The Creative Experiences Questionnaire

1. As a child, I thought that the dolls, teddy bears, and stuffed animals that I play with were $\quad$ YES NO leaving creatures

2. As a child, I strongly believed in the existence of dwarfs, elves, and other fairy tale figures $\quad$ YES NO

\begin{tabular}{l|l} 
3. As a child, I had my own make believe friend or animal & YES NO
\end{tabular}

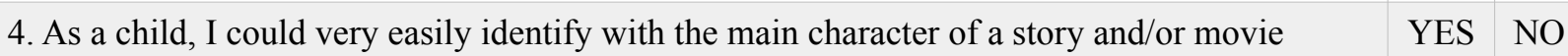

5. As a child, I sometimes had the feeling that I was someone else (e.g., a princess, an orphan, YES NO etc.)

6. As a child, I was encouraged by adults (parents, grandparents, brothers, sisters) to fully $\quad$ YES NO indulge myself in my fantasies and daydreams

7. As a child, I often felt lonely $\quad$ YES NO

8. As a child, I devoted my time to plying a musical instrument, dancing, acting, and/or $\quad$ YES NO drawing

\begin{tabular}{l|l} 
9. I spend more than half the day (daytime) fantasizing or daydreaming & YES NO
\end{tabular}

10. Many of my friends and/or relatives do not know that I have such detailed fantasies $\quad$ YES NO

\begin{tabular}{l|l} 
11. Many of my fantasies are often just as lively as a good movie & YES NO
\end{tabular}

\begin{tabular}{l|l} 
12. Many of my fantasies have a realistic intensity & YES NO
\end{tabular}

13. I foten confused fantasies with real memories $\quad$ YES NO

14. I am never too bored because I start fantasizing when things get boring $\quad$ YES NO

15. Sometimes I act as if I am somebody else and I completely identify myself with that role $\quad$ YES NO

\begin{tabular}{l|l} 
16. When I recall my childhood, I have very vivid and lively memories & YES NO
\end{tabular}

\begin{tabular}{l|l|l} 
17. I can recall many occurrences before the age of three & YES NO
\end{tabular}

\begin{tabular}{l|l} 
18. When I perceive violence on television, I get so into it that I get really upset & YES NO
\end{tabular}

\begin{tabular}{l|l|l} 
19. When I think of something cold, I actually get cold & YES NO
\end{tabular}

20. When I imagine I have eaten rotten food, I really get nauseous $\quad$ YES NO

21. I often have the feeling that I can predict things that are bound to happen in the future $\quad$ YES NO

22. I often have the experience of thinking of someone and soon afterwards that particular $\quad$ YES NO person calls or show up

23. I sometimes feel that I have had an out of body experience $\quad$ YES NO

24. When I sing or write something, I sometimes have the feeling that someone or something YES NO outside myself directs me

25. During my life, I have had intense religious experiences which influenced my in a very $\quad$ YES NO strong manner 
Appendix C

Demographic Questionnaire

What is your age?

How would you self-identify?

$\square$ Male

$\square$ Female

$\square$ Trans

$\square$ Other, please specify

$\square$ Prefer not to answer

To which of the following ethnic and/or cultural groups do you belong?

$\square$ 1. Aboriginal

$\square$ 2. Arab

$\square$ 3. Black

$\square$ 4. Chinese

$\square$ 5. Filipino

6. Japanese

$\square$ 7. Korean

$\square$ 8. Latin American

$\square$ 9. South Asian (e.g., East Indian, Pakistani, Sri Lankan, etc.)

$\square$ 10. Southeast Asian (e.g., Vietnamese, Cambodian, Malaysian, Laotian, etc.)

$\square$ 11. West Asian (e.g., Iranian, Afghan, etc.)

$\square$ 12. White

$\square$ 13. Other

$\square$ 14. Prefer not to answer 


\section{Appendix D \\ Logical Reasoning Task Questions}

1) Soda Executive: If that drink is fizzy, then it must be soda. That drink is definitely fizzy.

If the executive's statements are true, which of the following can be concluded?
a) The drink is not a soda
b) The drink is a soda
c) The drink is not fizzy
d) The drink is refreshing
e) None of the above are true

2) In order to do well on an exam, you must study hard. Marjorie did well on the exam.

Assuming the statements are true, which of the following can be concluded?

a) Marjorie could have done better on her exam

b) Marjorie did not study hard

c) Marjorie always studied before any exam

d) Marjorie studied hard for the exam

e) None of the above

3) Critic: The recently published novel written by Timothy Tucker would be believable only if the characters Nina and Maurice were both blind - that kind of light exposure would permanently damage their retinas. Yet by the end of the book, Nina and Maurice can still clearly see.

If the critic's statements are true, which of the following conclusions can be drawn?

a) Nina and Maurice wore protective glasses at all times

b) The novel is well written, but not believable

c) If Nina and Maurice were both blind, the novel would be believable

d) The novel written by Timothy Tucker cannot be described as believable

e) None of the above can be concluded

4) Lisa: I know I said that if I heard on more love song about a girl patiently waiting for her Prince Charming, I would shave all my hair off. Well the radio just played the new Minka song where she sings about the day her perfect man will come. I am most certainly a woman of my word.

If Lisa's statements are true, which of the following conclusions can logically be assumed?

a) Lisa did not shave her head 
b) Lisa's hair met its end and was shaved off by a razor

c) If Lisa does not claim she will do something, she will not do it

d) Lisa thought about shaving her head

e) None of the above can logically be concluded

5) All sports cars need servicing often. All minivans require infrequent servicing. The new deluxe Seabreeze is a hybrid of a minivan and a sports car. Therefore the Seabreeze needs moderate servicing.

Which of the following contains flawed reasoning most closely resemble the flawed reasoning used in the above arguments?

a) All employees who work industriously are given large bonuses. But some employees who do not work industriously also get large bonuses. Timothy works relatively industriously. Therefore Timothy gets a relatively large bonus.

b) All students attending Treetop University came from Greenbush High School. All students at Camden College previously attended Blue Mills High School. Children of the Turner family attend both Treetop University and Camden College. Therefore some of the children from the Turner family attended Greenbush High and some attended Blue Mills High.

c) All Product A boat cleaners are extremely toxic to marine life. All Product B boat cleaners are safe for marine life. Product $\mathrm{C}$ is a combination of Product $\mathrm{A}$ and Product $\mathrm{B}$. Product $\mathrm{C}$ is therefore moderately toxic.

d) All physicists know trigonometry. All chemists know calculus. Millie has worked as both a physicist and a chemist. Therefore, Millie knows trigonometry and calculus.

e) All of Lindsey's pies are delicious. All of Michelle's pies taste disgusting. One third of the pies in the pantry are delicious and two thirds are disgusting. Therefore one third of the pies were made by Lindsey and two thirds of the pies were made by Michelle.

6) Government official: At a recent conference on homeland security, many computer experts asserted that the most looming threat faced by government institutions, such as the FBI and CIA, is unauthorized access to highly confidential data. With awareness of this disturbing testimony, the government needs to prioritize the protection of our agent's confidentiality.

The government official's argument is most vulnerable to criticism by which of the following statements?

a) The argument mistakes the cause of the problem with the appropriate solution the problem

b) The argument relies on the testimony of experts whose expertise has not been proven to be sufficient to support the validity of heir claims

c) The argument confuses correlation between two incidents as evidence that one is the cause of the other.

d) The argument makes a broad generalization about a group based on information about the unrepresentative sample of the group 
e) The argument claims that confidential data belonging to certain government institutions belongs to all institutions

7) Consumer: My family says my computer will one day contract a virus because I download and send numerous SPAM e-mails from my laptop. However, I have painstakingly researched computer systems and supposedly desktops get far fewer viruses than do laptops. So if I trade in my laptop for a desktop, I will lower the risk of my computer getting a virus.

The reasoning of the consumer's argument is most vulnerable to the objection that he:

a) assumes causation while a simple correlation exists

b) relies on a small and unrepresentative sample

c) misinterprets evidence that a result is likely as evidence that the result is certain

d) mistakes a condition sufficient for bringing about a result for a condition necessary for doing so

e) relies on a source that has not been proven to have sufficient evidence and support

8) Ethics Professor: Any action is ethically and morally right if It would be reasonably expected to improve the situations of the majority of those impacted by the action. Any action is morally and ethically wrong if it could reasonably be expected to negatively affect the situations of the majority of the people impacted by it. Therefore actions are also right if they would reasonably be expected to result in no change in the situation of those affected by the decision.

The professor's conclusion logically follows if which one of the following statements is assumed?

a) Only wrong actions could reasonably be expected to negatively affect the situations of the majority of the people impacted by them.

b) No action can simultaneously be considered right and wrong

c) Any action that is not unethical or morally wrong is morally right

d) Some actions can reasonably be expected to not affect the situations of the people impacted by them

e) Good consequences are only caused by morally right actions

9) Airplane design companies obtain consumer data regarding such physically relevant factors as whether seating arrangements are spacious enough or personal entertainment sets are east to navigate. Nevertheless, direct designer communication with consumers is often preferred to survey information. This is because survey data may inform designers that satisfaction with a component is low, without explaining how this can be addressed and improved upon.

The reasoning in the argument is most alike which of the following assertions?

a) Airplane design institutions generally conduct highly thorough postmarket surveys. 
b) Airplane designs will not satisfactorily meet consumer demands if consumers are not consulted during the process

c) Designers desire to build features that will satisfy specific corners of the market

d) Consumer research for design alterations can assist in successful designs of products

e) Consumer data results in modifications that affect exterior as opposed to interior airplane designs

10) During Nazi era Germany, the German government had a major financial and commercial impact on painting and sculpture in Germany. Sponsorship by private individuals had drastically decreased during this era. Because the government discouraged innovation in the artistic community, few innovative works appeared in Nazi era German painting. Despite this, Nazi era German sculpture showed an astounding degree of innovation.

Which one of the following statements, if true, most explains the differences in the amount of innovative work produced by German sculptors and German painters in Nazi Germany?

a) In Nazi era Germany, the government provided greater financial support to sculpture than to painting

b) Greater numbers of painters were provided with government financial support in Nazi era Germany than sculptors, however individual sculptors were given more average support than were individual painters.

c) Stone was far more inexpensive than paint oils and canvas and therefore greater numbers of unsponsored sculptures were created in Nazi era Germany

d) Artists in Nazi era Germany that produced both sculptures and paintings were exceptionally rare

e) The German government provided the most substantial financial support to artists, but the total amount of financial support received by the art community declined during the Nazi era

11) After replacing her old texting plan with a new, cheaper plan with greater texting allowances, Nancy's phone bill increased.

All of the following, if accepted as true, help to explain the increase mentioned above EXCEPT:

a) The new texting plan allows for a smaller percentage of texting that Nancy uses than did the old plan

b) Not long after replacing her plan, Nancy's little sister began borrowing her phone on a consistent basis

c) While previously contacting her business colleagues through email, Nancy began using her phone more often to reach them

d) Nancy's phone company raised the texting rates after she switched her plan

e) Following the change to her new plan, Nancy's employers sent her on an overseas business trip where she continued to use her phone for text messages despite not having an international plan 
12) Many high schools in Pretoria recently began using inspirational posters to encourage their students to study harder to achieve high grades. However, almost all students at these schools already achieve high grades. Therefore the posters are unlikely to fulfill their intended purpose.

The reasoning in the argument is most vulnerable to criticism on the grounds that it:

a) Neglects the possibility that high schools that do not currently use inspirational posters would increase their students grades if they began using the posters

b) Assumes that, in regard to students motivation to obtain high grades, high schools that display inspirational posters are representative of all high schools in general

c) Does not satisfactorily consider the possibility that student grades are highly affected by factors other than how hard the students work

d) Neglects to consider that even if inspirational posters do not have one specific benefit for student's grades, they may have comparable and equally beneficial affects

e) Fails to consider the possibility that even if students already achieve high grades, the inspirational posters may result in a grade increase

13) Although box office sales for horror films have increased at a steady rate over the last 5 years, it can be expected that this trend will soon reverse. Traditionally, over two thirds of horror film tickets have been purchased by those from age 15 to 23 and the population of people in this age group is expected to decrease over the next 15 years.

Which of the following, if true would most seriously damage the argument?

a) Most adults 23 years and up have never bought a ticket to a horror film

b) Horror film rentals have decreased over the past 5 years

c) New special effects will create entirely scarier villains in the next 15 years

d) The variety of horror film genres is not likely to decline in the foreseeable future

e) Most of the individuals who have bought tickets to horror films over the past 5 years have been over the age of 23

14) Jerry: Tina claims that the majority of the members of the board of governors for the Genoa public library are vehemently opposed to reducing the funding for the acquisition of new rumenology books. The board did pass a notion opposing the funding cuts, but only 7 out of 25 members voted, with 3 in favour of the cuts. In addition, the 4 opposing votes represent significantly less than $1 \%$ of Genoa's library members. Therefore it cannot be assumed that the boards decision represent the opinion of the majority of Genoa's library members.

Which of the following most accurately describes Jerry's process of argumentation?

a) Questioning a conclusion based on voting results, because people who are biased are more likely to vote 
b) Questioning an assertion supported by statistical evidence by claiming that statistical evidence can be manipulated to provide support for he view the interpreter wants supported

c) Striving to discredit a claim by proving that, despite the claim, the truth of the conclusion is not logically drawn from the truth of the premises

d) Attempting to question the validity of a conclusion by asserting that the statistical sample is unrepresentative and inadequate to be trusted

e) Criticizing an opinion based on the argument that the opinion is supported by data that is impossible to refute

15) High school is in some ways akin to life itself, and when one approaches graduation, one begins to behave in ways similar to when one nears the end of one's life. Thus, as those in their twilight years devote significant time to looking back on their lifetimes, those nearing high school graduation...

Which of the following logically completes the argument?

a) reminisce about their own lives

b) begin to fear their own nearing demise

c) become fascinated in the events that occurred in their high school careers

d) look forward to the next stage of their lives

e) analyze why certain embarrassing high school incidents could have been avoided

16) John: Scientists have recently claimed that $68 \%$ of women choose their mates based on pheromones akin to those of their fathers. However, this claim should not be accepted, as all statistically precise claims should not be, as such specific claims could not be based on scientific fact.

Kelsey: While exactitude is not guaranteed in many facets of life, it is an acceptable phenomenon in many others. Several fields of science obtain highly specific results, which should not be questioned purely because of their precision.

Support is provided by the above statements for the belief that John and Kelsey would disagree about which of the following?

a) Scientific research might show that $68 \%$ of women choose their mates based on pheromones like this of their fathers

b) Certain fields of science can produce statistical results that should not be inherently doubted

c) Research into mate selection is a field where exact science and precision cannot reasonably be expected in a scientist's results

d) If inherently dubious findings are generally false, then most scientific findings are also false

e) It is able to be determined whether $68 \%$ of women choosing their mates do so based on pheromone similarity to their fathers 
17) Good grades are a requirement for any student who wants to run for student government. In addition, no individual with a suspension on his or her record may run for student government. Therefore, Alexander, a student majoring in biology who has both good grades and is on the Dean's list, cannot be voted in as student body president, since he has a suspension on his record.

The argument's conclusion is logically reached if which of the following is assumed to be true?

a) Only students eligible to run for student government can be elected as student body president b) Anyone who is on the Dean's list that does not have a record of suspension is eligible to run for student body president

c) Good grades are not necessary for the position of student body president

d) If Alexander did not have a record of suspension, he would be elected to the position of student body president.

e) The incident for which Alexander was suspended is relevant to the responsibilities of the position of student body president 
Appendix E

Confession Statement

The participant clicked the space bar and saw the answer. His/her data cannot be used.

\section{Participant signature}

Experimenter signature 
Appendix F

Follow-Up Questions

(1) Can you tell me what factors you considered when you were deciding whether or not to sign the statement?

(2) Did anything of the [insert condition] play a role in your decision to sign or not sign?

(3) Anything else that caused you to make the decision to sign or not to sign?

(4) Did you at any point think that you had clicked the space bar? Explain. 


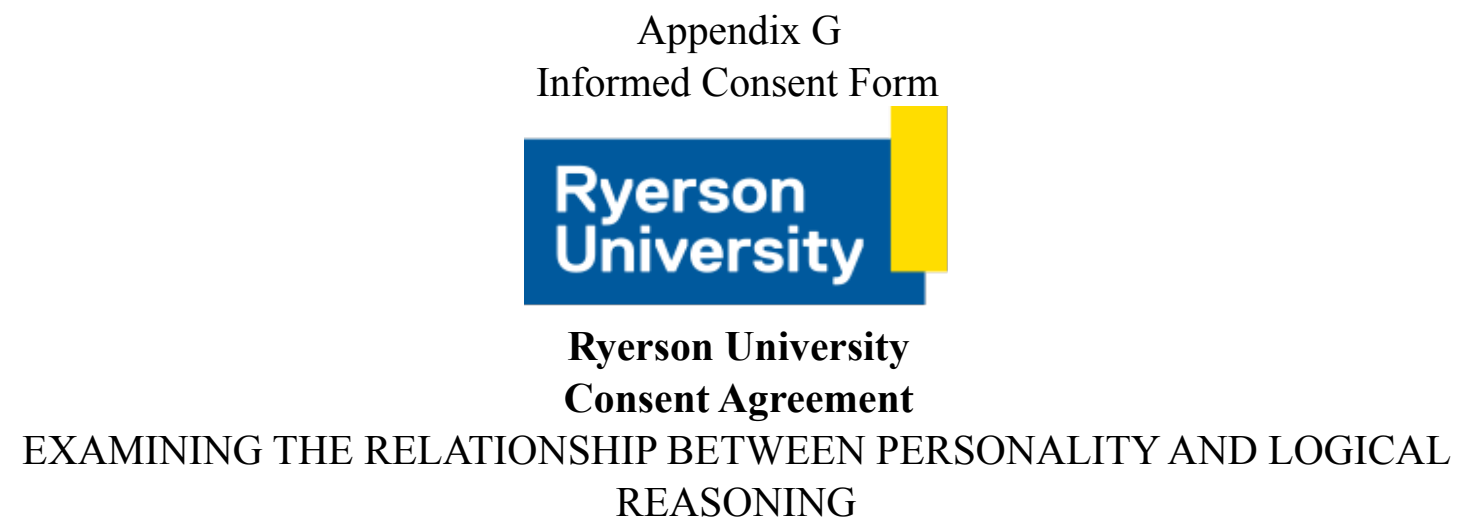

You are being asked to participate in a research study. Before you give your consent, it is important that you read the following information and ask as many questions as necessary to be sure you understand what you will be asked to do.

Primary Investigator: Leah Hamovitch

M.A. Student

Department of Psychology

Co-Investigators: $\quad$ Dr. Tara Burke

Associated Professor

Department of Psychology

Purpose of the Study: The purpose of this 60 minute, 1 credit social psychological study is to examine the relationship between personality traits and performance on logical reasoning tasks. Approximately 210 Ryerson Students enrolled in PSY102 and PSY202 will participate in this study.

Description of the Study: If you decide to participate in this research, you will be asked to do the following: Answer a set of logical reasoning tasks on the computer. You will then answer some brief questionnaires assessing various aspects of your personality. You will be given 1 course credit for participating.

What is Experimental in this Study: From a technical or procedural point of view, part of this study is considered "experimental," because by following the procedure described above, the study examines the impact of one variable (called the "independent variable") on another variable ("called the dependent variable"). You will be given more information about the independent and dependent variables in this study at the end of today's session.

Risks or Discomforts: This is a minimal risk study. Any discomfort is expected to be temporary and not greater than you might experience in a typical day. Occasionally people may feel 
uncomfortable when answering questionnaires that ask about attitudes toward personal issues. While we do not anticipate that any of the questions you will be responding to are of this nature, if any aspect of this study makes you feel uncomfortable, you may choose not to answer certain questions, or to withdraw from the study at any time and still receive your credit.

Benefits of the Study: We anticipate that you will benefit from this study by learning more about social psychological research. When the session is over, we will describe the purpose and hypotheses of the study to you in more detail. Also, once we have completed data collection and analyses (Winter 2019) you are welcome to contact the researchers via email to view the results.

Confidentiality: Your responses in this research will be confidential and anonymous; your name will not be linked to your responses. Any materials that include your name - this consent formwill be stored separately from any other data for a minimum of 5 years. Physical materials will be stored in a locked filing cabinet in a locked room, and computer files will be stored on password-protected computers. Only the investigator and other Psychology and Law lab personnel will have access to this information. Your responses on any questionnaires will be identified only by a participant number assigned to you by the researchers. This number cannot later be used to identify you and is unrelated to your Sona ID or student number. The online questionnaire is hosted by Qualtrics, which is an American company. Consequently, Qualtrics or USA authorities may access survey data in some forms (e.g., aggregate usage information) and under strict policies. Qualtrics employs a variety of security features to make sure that the data collected are not accessible by outside bodies. More information on Qualtrics' security systems can be viewed here: https://www.qualtrics.com/security-statement/. Information regarding their protective privacy policy is available here: https://www.qualtrics.com/privacy-statement/ . Although Qualtrics usually stores IP address data, we have deactivated that function for this study

Incentives to Participate: You will receive 1course credit for your Introductory Psychology course. If you would prefer to walk through of the study - that is, if you would like to observe the research process but not provide any personal data - you will still be given 1 course credit. Note that while you can take part in as many psychology research studies as you wish, you cannot exceed the maximum allotted course credits, as set by your Introductory Psychology course.

Voluntary Nature of Participation: Participation in this study is voluntary. Your choice of whether or not to participate will not influence your future relations with Ryerson University. If you decide to participate, you are free to withdraw your consent and to stop your participation at any time. Should you withdraw from the study, or if you choose not to answer some questions, you will still be given your 1 course credit (provided you have not already received the maximum allotted for research participation for the term).

Dissemination of Results: Anonymized data may be provided to other researchers for the purpose of study or verification of results; any data that is shared will NOT include the names of 
ANY participants. It is possible that a third party (e.g., graduate students, senior undergraduate students) may have access to the data for a purpose that was not originally identified in this study. As well, results may be shared with others at scholarly meetings or as part of published papers. However, all information will be presented in aggregate form. That is, none of your individual information will be identifiable in any way.

Questions about the Study: If you have any questions about the research now, please ask. If you have questions later about the research, you may contact.

Leah Hamovitch, 416, 979-5000 x 2190 leah.hamovitch@psych.ryerson.ca

Dr. Tara Burke, 416-979-5000, ex. 6519, tburke@psych.ryerson.ca

If you have questions regarding your rights as a human subject and participation in this study, please contact the Ryerson University Research Ethics Board: Ryerson Ethics Board, c/o Office of the Vice President, Research and Innovation, Ryerson University 350 Victoria Street Toronto, ON M5B 2K3, 416-979-5042, rebchair@,ryerson.ca

If you have questions about your participation in the Introductory Psychology Participant Pool, please contact thepool@psych.ryerson.ca 


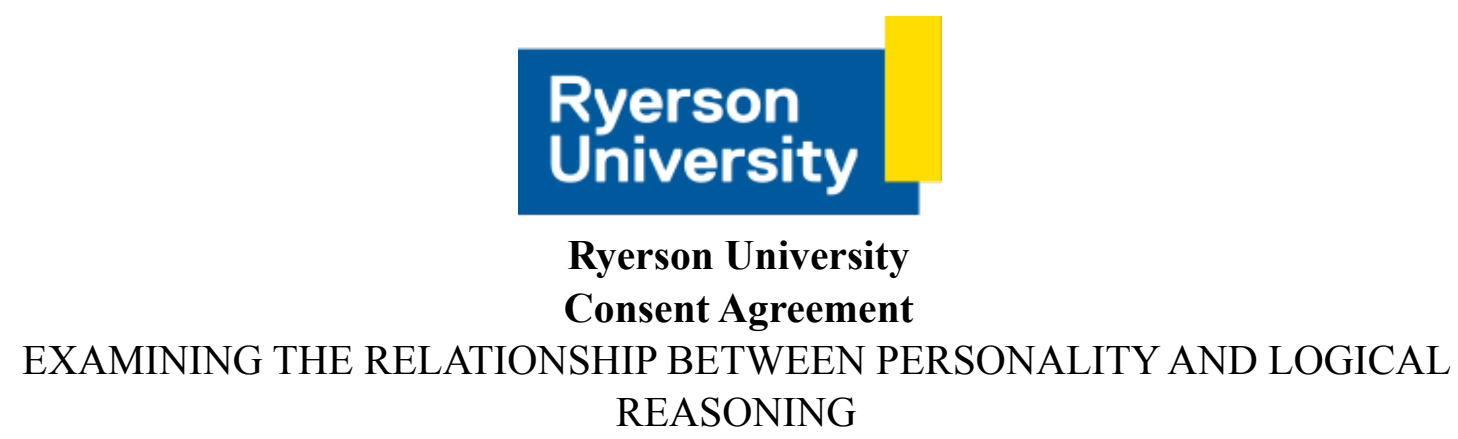

Agreement: Your signature below indicates that you have read the information in this agreement and have had a chance to ask any questions you have about the study. Your signature also indicates that you agree to be in the study and have been told that you can change your mind and withdraw your consent to participate at any time.

Name of Participant (please print)

Signature of Participant

Date

Signature of Investigator

Date

Your signature below indicates that you agree to be audio-recorded during the duration of the study. All audio data will be transcribed and deleted:

Signature of Participant

Date

Signature of Investigator

Date 
Appendix $\mathrm{H}$

False Photograph Evidence Script

$<$ Experimenter comes into the testing room $>$

Experimenter: "Did you click the 'space bar' during the task? Were you shown the answer?"

If participant denies the allegation....

$<$ Experimenter exists the testing room and returns after 2 minutes $>$

Experimenter: "We have a camera in here that records the experiments and there is footage of you being shown the answer during the task. Here is photograph of you. As you can see, it shows here were then shown answer on the screen at some point during the task"

$<$ Experimenter hands the photo to the participant to look at $>$

Experimenter: "So at this point I will ask again if you clicked the space bar. The reason we need to know is because it does taint the integrity of the experiment if you saw the answers, and we'll need to make note of this."

If participant admit that they did it...

Experimenter: "I will have you sign this note <experimenter handwrites confession statement> which indicates that you clicked the space bar and saw that and that we can't use your data. I need this on the record for reference for why your data will not be used for analysis."

If participant doesn't agree after the first time asking....

Experimenter: "The photograph does show that you were shown the answer, which means that we cannot use your data. Signing this note will be helpful as it will indicate why your data cannot be used for analysis."

*If participant agrees after the second request, the experimenter will handwrite the confession statement and have the participant sign. If not, the experimenter will end the experiment here* 
Appendix I

False Photograph Evidence

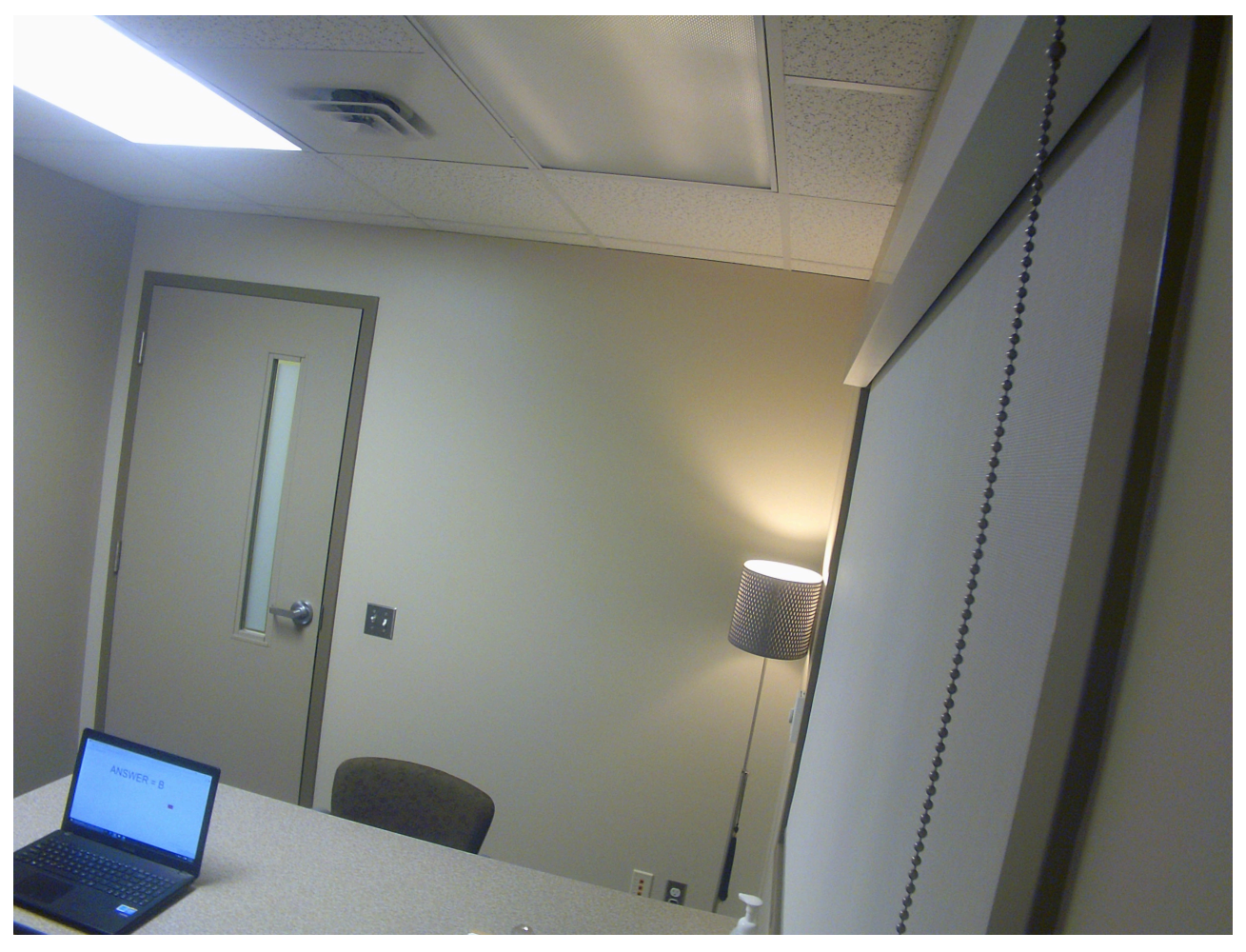




\section{Appendix $\mathbf{J}$}

False Physical Evidence Script

$<$ Experimenter comes into the testing room $>$

Experimenter: "Did you click the 'Space bar' during the task? Were you shown the answer?"

If participant denies the allegation....

$<$ Experimenter exists the testing room and returns after 2 minutes $>$

Experimenter: "We have a keyboard tracker attached to the computers and it indicated that you did in fact click the space bar and were shown the answer during the task. As you can see, $<$ experimenter shows participant the line that indicates that s/he clicked the space bar> you did in fact click the space bar at some point during the task."

$<$ Experimenter hands the record to the participant to look at $>$

Experimenter: "So at this point I will ask again if you clicked the space bar. The reason we need to know is because it does taint the integrity of the experiment if you saw the answers, and we'll need to make note of this."

If participant agrees that they did it...

Experimenter: "I will have you sign this note <experimenter handwrites confession statement> which indicates that you clicked the space bar and that we can't use your data. I need this on the record for reference for why your data will not be used for analysis."

If participant doesn't agree after the first time asking....

Experimenter: "If you tell us that you clicked it, you will not get in trouble and you will still receive your credit. But the keyboard tracker does indicate that the space bar was pressed, which means that we cannot use your data. So signing this note will be helpful as it will indicate why your data cannot be used for analysis."

*If participant agrees after the second request, the experimenter will handwrite the confession statement and have the participant sign. If not, the experimenter will end the experiment here* 
Appendix K

False Keyboard Tracking Report

\begin{tabular}{|c|c|}
\hline 믐 InputManager Library - Hook example & \begin{tabular}{|l|l|l|}
$口$ & 回 & $\mathbf{X}$ \\
\end{tabular} \\
\hline $\begin{array}{l}\text { The mouse cursor moved to: } 796,605 \\
\text { The mouse cursor moved to: } 797,605 \\
\text { The mouse cursor moved to: } 797,604 \\
\text { The mouse cursor moved to: } 798,604 \\
\text { The mouse cursor moved to: } 799,604 \\
\text { The mouse cursor moved to: } 799,603 \\
\text { The mouse cursor moved to: } 800,603 \\
\text { The mouse cursor moved to: } 800,602 \\
\text { The mouse cursor moved to: } 801,602 \\
\text { The mouse cursor moved to: } 801,603 \\
\text { Mouse button changed state to: RightDown } \\
\text { Mouse button changed state to: RightUp } \\
\text { Mouse button changed state to: LeftDown } \\
\text { Mouse button changed state to: LeftUp } \\
\text { User released Space } \\
\text { User released LControlKey } \\
\text { User holds Space } \\
\text { User holds LControlKey } \\
\text { User released Space } \\
\text { User released LControlKey } \\
\text { User holds Space } \\
\text { User holds LControlKey }\end{array}$ & $\square$ \\
\hline User released End & 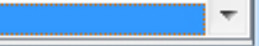 \\
\hline
\end{tabular}


Appendix L

False Eyewitness Testimony Script

$<$ Experimenter comes into the testing room $>$

Experimenter: "Did you click the 'space bar' during the task? Were you shown the answer?"

If participant denies the allegation....

$<$ Experimenter exists the testing room and returns after 2 minutes $>$

Experimenter: "My research assistant is in the other room and was instructed to watch and ensure that the experiment was running smoothly. She indicated to me that she saw you click the space bar button and saw the answer flash on the screen. Here's the note that indicates that she saw this happen."

$<$ Experimenter hands the note to the participant $>$

Experimenter: "So at this point I will ask again if you clicked the space bar. The reason we need to know is because it does taint the integrity of the experiment if you saw the answers, and we'll need to make note of this."

If participant agrees that they did it...

Experimenter: "I will have you sign this note <experimenter handwrites confession statement> which indicates that you clicked the space bar and that we can't use your data. I need this on the record for reference for why your data will not be used for analysis."

If participant doesn't agree after the first time asking....

Experimenter: "My research assistant did see it happen, and if it did, then that means that we cannot use your data. So signing this note will be helpful as it will indicate why your data cannot be used for analysis."

*If participant agrees after the second request, the experimenter will handwrite the confession statement and have the participant sign. If not, the experimenter will end the experiment here* 
Appendix M

Sample Research Assistant Note

\begin{tabular}{|l|l|l|l|}
\hline SONA ID & Date & Participated (Y/N) & Notes \\
\hline 123456 & February 282018 & Yes & $\begin{array}{l}\text { Participant clicked the space bar and saw the } \\
\text { answer. Can't use data. }\end{array}$ \\
\hline
\end{tabular}


Appendix N

Bluffed Photograph Evidence Script

$<$ Experimenter comes into the testing room $>$

Experimenter: "Did you click the 'space bar' during the task? Were you shown the answer?"

If participant denies the allegation....

$<$ Experimenter exists the testing room and returns after 2 minutes $>$

Experimenter: "What if I told you we had that camera aimed at you, so I will be able to check the later to see if there is footage of you clicking the space bar?"

If participants continues to deny the allegations....

Experimenter: "I don't have time now to go through the camera footage and print the image, but the footage does exist and when I have access to it, it could confirm that you did in fact click the space bar. So at this point I will ask again if you clicked the space bar. The reason we need to know is because it does taint the integrity of the experiment if you saw the answers, and we'll need to make note of this."

If participant agrees that they did it...

Experimenter: "I will have you sign this note <experimenter handwrites confession statement> which indicates that you clicked the space bar and that we can't use your data. I need this on the record for reference for why your data will not be used for analysis."

If participant doesn't agree after the first time asking....

Experimenter: "When I check the camera footage, it will be able to tell me if you clicked the space bar and were shown the answer. So signing this note will be helpful as it will indicate why your data cannot be used for analysis."

*If participant agrees after the second request, the experimenter will handwrite the confession statement and have the participant sign. If not, the experimenter will end the experiment here* 
Appendix O

Bluff Physical Evidence Script

$<$ Experimenter comes into the testing room $>$

Experimenter: "Did you click the 'space bar' during the task? Were you shown the answer?"

If participant denies the allegation....

$<$ Experimenter exists the testing room and returns after 2 minutes $>$

Experimenter: "What if I told you that the computer is connected to a keyboard tracking device that could show me whether you pressed the space bar and saw the answers?

If participants continues to deny the allegations....

Experimenter: "The keyboard tracking system is password protected by my supervisor, so I can't print it out for you right now and show you, but when I do, it will be able to show me whether or not you clicked the space bar. So at this point I will ask again if you clicked the space bar. The reason we need to know is because it does taint the integrity of the experiment if you saw the answers, and we'll need to make note of this."

If participant agrees that s/he did it...

Experimenter: "I will have you sign this note <experimenter handwrites confession statement> which indicates that you clicked the space bar and that we can't use your data. I need this on the record for reference for why your data will not be used for analysis."

If participant doesn't agree after the first time asking....

Experimenter: "If the keyboard tracker indicates that the space bar was pressed, it means that we cannot use your data. So signing this note will be helpful as it will indicate why your data cannot be used for analysis."

*If participant agrees after the second request, the experiment will handwrite the confession statement and have the participant sign. If not, the experimenter will end the experiment here* 
Appendix $\mathrm{P}$

Bluffed Eyewitness Testimony Script

$<$ Experimenter comes into the testing room $>$

Experimenter: "Did you click the 'space bar' during the task? Were you shown the answer?"

If participant denies the allegation....

$<$ Experimenter exists the testing room and returns after 2 minutes $>$

Experimenter: "What if I told you that my research assistant was instructed to watch you during the experiment and take notes, so she will be able to tell me if she saw you click the space bar and see the answer?"

If participant continues to deny the allegations....

Experimenter: "My research assistant isn't around anymore, but I will be able to ask her and to check with her notes to see if you clicked the space bar at any point during the experiment. So at this point I will ask again if you clicked the space bar. The reason we need to know is because it does taint the integrity of the experiment if you saw the answers, and we'll need to make note of this."

If participant agrees that s/he did it...

Experimenter: "I will have you sign this note <experimenter handwrites confession statement $>$ which indicates that you clicked the Space bar and that we can't use your data. I need this on the record for reference for why your data will not be used for analysis."

If participant doesn't agree after the first time asking....

Experimenter: "But my research assistant watched you during the experiment and will be able to tell me if she saw you click the space bar, and if you did, we cannot use your data. So signing this note will be helpful as it will indicate why your data cannot be used for analysis."

*If participant agrees after the second request, the experimenter will handwrite the confession statement and have the participant sign. If not, the experimenter will end the experiment here* 
Appendix Q

Debriefing Form

\section{Debrief - Is The Bluff Enough?}

The study you just participated in examined the effects of false evidence on false confession rates. More than 1 out of 4 people wrongfully convicted but later exonerated by DNA evidence made a false confession (The Innocence Project, 2018). Legal scholars and researchers consider a confession to be the most potent form of evidence as it is compelling and persuasive for a jury, and damaging to the defendant (Kassin et al., 2010). To date, the majority of false confession cases are the result of police coercion and psychologically manipulative interrogation techniques. Interrogators will sometimes present false evidence in order to elicit a confession (Kassin et al., 2007). Alternatively, interrogators may use the bluff ploy, in which they pretend to have evidence without additionally asserting that it necessarily implicates the suspect (Perillo \& Kassin, 2011). The present study aims to contribute to our understanding of the influence of the presentation of false evidence on false confession rates.

The current study examined the effect of three different forms of false evidence on confession rates. We also examined the difference between the false evidence ploy and the bluff ploy. All of the participants completed the logical reasoning questions on the computer, and everyone was given the instruction that the space bar was not to be pressed. Participants were then presented with false evidence (the independent variable) and asked to sign a confession (the dependent variable). Half of the participants were physically shown evidence (the false evidence conditions) and were shown either a photograph, keyboard tracking, or an eyewitness statement. The other half were simply told that this evidence exists (the bluff ploy conditions). Everyone was asked follow-up questions to help us understand the underlying mechanisms behind why people choose to confess to something that they did not do (i.e., a false confession). The followup questions were also designed to test for rates of internalization, (whether participants genuinely came to believe that they clicked the space bar) (a dependent variable). It is very important to note that you did not click the space bar, and that you did absolutely nothing wrong to violate the experimental protocol in any way. This was solely for the purpose of the study.

Based on a growing number of studies that suggest images are an especially persuasive form of evidence (e.g., Kassin \& Dunn, 1997; McCabe \& Castel, 2008), along with research on the power on the physical and technical evidence, our first hypothesis was that false photograph evidence will be the most effective in eliciting false confessions, followed by false physical evidence, and false eyewitness testimony. Our second hypothesis was that there would be no significant difference overall in confession rates between those in the false evidence conditions and those the bluff ploy conditions (i.e., that the bluff ploy is just as powerful as the false evidence ploy). Research suggests that when participants are confronted with an accusation of guilt, they turn to the available external evidence to help them decide whether or not they committed the act. Moreover, research has shown that post-event information can lead people to 
recall events differently from the way they actually occurred, or even to recall false events that never occurred (Sacchi, Agnoli \& Loftus, 2007). Therefore, our third hypothesis was that those in the false evidence conditions will be more likely to internalize the behaviour (i.e., will be more likely to genuinely come to believe that they clicked the space bar) than those in the bluff conditions.

The results of the study will allow us to identify whether certain variants of the false evidence ploy are more powerful in eliciting false confessions than others and whether the bluff ploy and the false evidence ploy are differentially impactful. The information may help to inform the justice system and police practices in general and in particular, it may help prevent future false confessions and wrongful convictions.

If you know of others who will be participating in this experiment, please refrain from discussing it with them. We do not want our future participants to be aware of the procedures and expected findings. If you would like a copy of the findings, you are invited to contact us via e-mail once the study is complete (Summer 2019).

Thank you for participating in our research. If you have any questions about the study, please feel free to contact:

Dr. Tara Burke, 416-979-5000 x 6519; tburke@psych.ryerson.ca

Leah Hamovitch, 416-979-5000, x2190, leah.hamovitch@psych.ryerson.ca

If you have any questions about receiving your Psychology 102/202 credit participation, please contact: thepool@psych.ryerson.ca

If you found this experiment to be emotionally upsetting or you feel any distress/anxiety after participating in this study, please feel free to contact the Ryerson Centre for Student Development and Counselling at 416-979-5195, Room JOR 07C. You may also contact the Toronto Distress Centre at 416-408-HELP (4357).

If you have any questions regarding your rights as a human subject and participation in this study, you may contact the Ryerson University Research Ethics Board for information: Research Ethics Board, c/o: Office of the Vice President, Research and Innovation, Ryerson University, 350 Victoria Street, Toronto, ON, M5B 2K3, 416-979-5042, rebchair@ryerson.ca

\section{References:}

Kassin, S. M., \& Dunn, M. A. (1997). Computer-animated displays and the jury: Facilitative and prejudicial effects. Law and Human Behavior, 21(3), 269-281. doi:10.1023/a: 1024838715221

Kassin, S. M., Drizin, S. A., Grisso, T., Gudjonsson, G. H., Leo, R. A., \& Redlich, A. D. (2010). Police-induced confessions, risk factors, and recommendations: Looking ahead. Law and Human Behavior, 34(1), 49-52. doi:10.1007/s10979-010-9217-5 
Kassin, S. M., Leo, R. A., Meissner, C. A., Richman, K. D., Colwell, L. H., Leach, A.-M., et al. (2007). Police interviewing and interrogation: A self-report survey of police practices and beliefs. Law and Human Behavior, 31, 381-400.

McCabe, D. P., \& Castel, A. D. (2008). Seeing is believing: The effect of brain images on judgments of scientific reasoning. Cognition, 107(1), 343-352. doi:10.1016/j.cognition. 2007.07.017

Perillo, J. T., \& Kassin, S. M. (2011). Inside interrogation: The lie, the bluff, and false confessions. Law and Human Behavior, 35, 327-337. doi:10.1007/s10979-010-9244-2

Sacchi, D. L., Agnoli, F., \& Loftus, E. F. (2007). Changing history: Doctored photographs affect memory for past public events. Applied Cognitive Psychology, 21, 1005-1022. 


\section{Appendix R}

Re-Consent Form

I understand the true purpose of the study I have completed and I consent to the use of my data.

Signature of Participant

Date 


\section{References}

Blair, J. P. (2007). The roles of interrogation, perception, and individual differences in producing compliant false confessions. Psychology, Crime, and the Law, 13, 173-186

Bond, J. C., \& Depaulo, B. M. (2006). Accuracy of deception judgments. Personality and Social Psychology Review, 10(3). doi:10.1207/s15327957pspr1003_2a

Davis, D., \& O’Donohue, W. T. (2004). The road to perdition: "Extreme influence" tactics in the interrogation room. In W. T. O’Donohue, E. Levensky (Eds.) Handbook of Forensic Psychology (pp. 897-996). New York, Elsevier Academic Press.

Drizin, S. A., \& Leo, R. A. (2004). The problem of false confessions in the post-DNA world. North Carolina Law Review, 82, 891-1007.

Exoneration cases. Retrieved January 24, 2019, from http://www.law.umich.edu/special/ exoneration/Pages/about.aspx

False confessions or admissions. Retrieved January 24 2019, from https:// Www.innocenceproject.org/causes/false-confessions-admissions/

Firstman, R., \& Salpeter, J. (2008). A criminal injustice. A true crime, a false confession, and the fight to the free Marty Tankleff. New York, NY: Ballantine Books.

Forrest, K. D., Wadkins, T. A., \& Miller, R. L. (2002). The role of preexisting stress on false confessions: An empirical study. Journal of Credibility Assessment and Witness Psychology, 3, 23-45.

Forrest, K. D., Woody, W. D., Brady, S. E., Batterman, K. C., Stastny, B. J., \& Bruns, J. A. (2012). False-evidence ploys and interrogations: Mock jurors perceptions of false- 
evidence ploy type, deception, coercion, and justification. Behavioral Sciences \& the Law, 30(3), 342-364. doi:10.1002/bsl.1999

Gohara, M. (2006). A lie for a lie: False confessions and the case for reconsidering the legality for deceptive interrogation techniques. Fordham Urban Law Journal, 33, 791-842.

Gudjonsson, G. H. (1989). Compliance in an interrogative situation: A new scale. Personality and Individual Differences, 10(5), 535-540. doi:10.1016/0191-8869(89)90035-4

Gudjonsson, G. H. (1999). The psychology of interrogations, confessions and testimony. Chichester: Wiley.

Gudjonsson, G. H. (2003). The psychology of interrogations and confessions: A handbook. Chichester, UK: John Wiley.

Gudjonsson, G. H. (2011). The psychology of false confessions: A review of the current evidence. In Police interrogation and false confessions: Current research, practice, and policy recommendations (pp. 31-44). Washington, DC: American Psychological Association.

Hartwig, M., \& Bond, C. R. (2011). Why do lie-catchers fail? A lens model meta-analysis of human lie judgments. Psychological Bulletin. doi:10.1037/a0023589.supp

Horgan, A. J., Russano, M. B., Meissner, C. A., \& Evans, J. R. (2012). Minimization and maximization techniques: Assessing the perceived consequences of confessing and confession diagnosticity. Psychology, Crime \& Law, 18, 65-78. doi: 10.1080/1068316X. 2011.561801. 
Horselenberg, R., Merckelbach, H., \& Josephs, S. (2003). Individual differences and false confessions: A conceptual replication of Kassin and Kiechel (1996). Psychology, Crime \& Law, 9(1), 1-8. doi:10.1080/10683160308141

Horselenberg, R., Merckelbach, H., Smeets, T., Franssens, D., Peters, G. Y., \& Zeles, G. (2006). False confessions in the lab: Do plausibility and consequences matter? Psychology, Crime \& Law, 12(1), 61-75. doi:10.1080/1068310042000303076

Inbau, F. E., Reid, J. E., Buckley, J. P., \& Jayne, B. C. (2001). Criminal interrogation and confessions (4th ed.). Gaithersberg, MD: Aspen.

Innocence Canada (2019). Exonerations. Retrieved from http://www.innocencecanada.com/

Johnson, M. K., Foley, M. A., Suengas, A. G., \& Raye, C. L. (1988). Phenomenal characteristics of memories for perceived and imagined autobiographical events. Journal of Experimental Psychology: General, 117, 371-376.

Kassin, S. M. (1997). The psychology of confession evidence. American Psychologist, 52, 221233.

Kassin, S. M. (2005). On the psychology of confessions: Does innocence put innocents at risk? American Psychologist, 60, 215-228.

Kassin, S. M. (2006). A critical appraisal of modern police interrogations. In T. Williamson (Ed.), Investigative interviewing: Rights, research, regulation (pp. 207-228). Cullompton, Devon, UK: Willan Publishing.

Kassin, S. M. (2012). Why confessions trump innocence. American Psychologist, 67(6), 431-445. doi:10.1037/a0028212

Kassin, S. M. (2014). False confessions: Causes, consequences, and implications for reform. 
Policy Insights from the Behavioral and Brain Sciences, 1(1), 112-121. doi

$10.1177 / 2372732214548678$

Kassin, S. M. (2017). False confessions. Wiley Interdisciplinary Reviews: Cognitive Science, 8(6). doi:10.1002/wcs. 1439

Kassin, S. M., \& Dunn, M. A. (1997). Computer-animated displays and the jury: Facilitative and prejudicial effects. Law and Human Behavior, 21(3), 269-281. doi:10.1023/a: 1024838715221

Kassin, S. M., \& Fong, C. T. (1999). “I'm innocent!”: Effects of training on judgments of truth and deception in the interrogation room. Law and Human Behavior, 23, 499-516.

Kassin, S. M., \& Gudjonsson, G. H. (2004). The psychology of confessions. Psychological Science in the Public Interest, 5(2), 33-67. doi:10.1111/j.1529-1006.2004.00016.x

Kassin, S. M., \& Kiechel, K. L. (1996). The social psychology of false confessions: Compliance, internalization, and confabulation. Psychological Science, 7(3), 125-128. doi: 10.1111/j.1467-9280.1996.tb00344.x

Kassin, S.M., \& Neumann, K. (1997). On the power of confession evidence: An experimental test of the fundamental difference hypothesis. Law and Human Behavior, 21, 469-484.

Kassin, S. M., \& Norwick, R. (2004). Why people waive their Miranda rights: The power of innocence. Law and Human Behavior, 28, 211-221.

Kassin, S. M., \& Sukel, H. (1997). Coerced confessions and the jury: An experimental test of the "harmless error" rule. Law and Human Behavior, 21(1), 27-46. doi:10.1023/a: 1024814009769

Kassin, S. M., Appleby, S. C., \& Perillo, J. T. (2010). Interviewing suspects: Practice, science, 
and future directions. Legal and Criminological Psychology, 15(1), 39-55.

Kassin, S. M., Goldstein, C. C., \& Savitsky, K. (2003). Behavioral confirmation in the interrogation room: On the dangers of presuming guilt. Law and Human Behavior, 27(2), 187-203. doi:10.1023/a:1022599230598

Kassin, S. M., Redlich, A. D., Alceste, F., \& Luke, T. J. (2018). On the general acceptance of confessions research: Opinions of the scientific community. American Psychologist, 73(1), 63-70.

Kassin, S. M., Drizin, S. A., Grisso, T., Gudjonsson, G. H., Leo, R. A., \& Redlich, A. D. (2010). Police-induced confessions, risk factors, and recommendations: Looking ahead. Law and Human Behavior, 34(1), 49-52. doi:10.1007/s10979-010-9217-5

Kassin, S. M., Leo, R. A., Meissner, C. A., Richman, K. D., Colwell, L. H., Leach, A.-M., et al. (2007). Police interviewing and interrogation: A Self-report survey of police practices and beliefs. Law and Human Behavior, 31, 381-400.

Klaver, J. R., Lee, Z., \& Rose, V. G. (2008). Effects of personality, interrogation techniques and plausibility in an experimental false confession paradigm. Legal and Criminological Psychology, 13(1), 71-88. doi:10.1348/135532507x193051

Leo, R. A. (1996). Inside the interrogation room. Journal of Criminal Law and Criminology, 86, 266-303.

Leo, R. A. (2005). Rethinking the study of miscarriages of justice: Developing a criminology of wrongful conviction. Journal of Contemporary Criminal Justice, 21(3), 201-223. doi: $10.1177 / 1043986205277477$ 
Leo, R. A. (2008). Police interrogation and American justice. Cambridge, MA: Harvard University Press.

Leo, R. A., \& Drizin, S. A. (2011). The three errors: Pathways to false confession and wrongful conviction. In Police interrogations and false confessions: current research, practice, and policy recommendations (pp. 9-27). Washington, DC: American Psychological Association.

Leo, R.A., \& Ofshe, R.J. (1998). The consequences of false confessions: Deprivations of liberty and miscarriages of justice in the age of psychological interrogation. Journal of Criminal Law and Criminology, 88, 429-296.

McCabe, D. P., \& Castel, A. D. (2008). Seeing is believing: The effect of brain images on judgments of scientific reasoning. Cognition, 107(1), 343-352. doi:10.1016/j.cognition. 2007.07.017

Meissner, C.A. \& Kassin, S.M. (2002). “He’s guilty!” Investigator bias in judgments of truth and deception, Law and Human Behavior, 26, 469-80.

Meissner, C. A., Russano, M. B., \& Narchet, F. M. (2011). The importance of a laboratory science for improving the diagnostic value of confession evidence. In Police interrogations and false confessions: Current research, practice, and policy recommendations (pp. 111-126). Washington, DC: American Psychological Association.

Meissner, C. A., Redlich, A. D., Michael, S. W., Evans, J. R., Camilletti, C. R., Bhatt, S., \& Brandon, S. (2014). Accusatorial and information-gathering interrogation methods and their effects on true and false confessions: a meta-analytic review. Journal of Experimental Criminology, 10(4), 459-486. doi:10.1007/s11292-014-9207-6 
Moston, S., Stephenson, G. M., \& Williamson, T. M. (1992). The effects of case characteristics on suspect behaviour during questioning. British Journal of Criminology, 32, 23-40.

Narchet, F. M., Meissner, C. A., \& Russano, M. B. (2011). Modeling the influence of investigator bias on the elicitation of true and false confessions. Law and Human Behavior, 35, 452465. doi: 10.1007/s10979-010-9257-X.

Nash, R. A., \& Wade, K. A. (2009). Innocent but proven guilty: Eliciting internalized false confessions using doctored-video evidence. Applied Cognitive Psychology, 23(5), 624-637. doi:10.1002/acp.1500

Nash, R. A., Wade, K. A., \& Brewer, R. J. (2009). Why do doctored images distort memory? Consciousness and Cognition, 18(3), 773-780. doi:10.1016/j.concog.2009.04.011

National Registry of Exonerations. (2019). Summary List of Exonerations. Retrieved from http://www.law.umich.edu/special/exoneration/Pages/about.aspx

Newring, K. A. B., \& O’Donohue, W. (2008). False confessions and influenced witnesses. Applied Psychology in Criminal Justice, 4, 81-108.

Ofshe, R. J. (1989). Coerced confessions: The logic of seemingly irrational action. Cultic Studies Journal, 6, 1-15.

Ofshe, R. J. (1992). Inadvertent hypnosis during interrogation: False confessions due to dissociative state; mis-identified multiple personality and the satanic cult hypothesis. The International Journal of Clinical and Experimental Hypnosis, XL, 125-156.

Ofshe, R. J., \& Leo, R. A. (1997). The decision to confess falsely: Rational choice and irrational action. Denver University Law Review, 74, 979-1122. 
Ofshe, R. J., \& Leo, R. A. (1997). The social psychology of police interrogation: The theory and classification of true and false confessions. Studies in Law Politics and Society, 16, 189-254.

Perillo, J. T., \& Kassin, S. M. (2011). Inside interrogation: The lie, the bluff, and false confessions. Law and Human Behavior, 35, 327-337. doi:10.1007/s10979-010-9244-2

Redlich, A. D., \& Goodman, G. S. (2003). Taking responsibility for an act not committed: The influence of age and suggestibility. Law and Human Behavior, 27(2), 141-156. doi: 10.1023/a:1022543012851

Redlich, A D., \& Meissner, C. A (2009). Techniques and controversies in the interrogation of suspects: The artful practice versus the scientific study. In J. Skeem et al. (Eds.), Psychological science in the courtroom: Controversies and consensus (pp. 124-148). New York: Guilford Press.

Russano, M. B., Meissner, C. A., Narchet, F. M., \& Kassin, S. M. (2005). Investigating true and false confessions within a novel experimental paradigm. Psychological Science, 16, 481486.

Sacchi, D. L., Agnoli, F., \& Loftus, E. F. (2007). Changing history: Doctored photographs affect memory for past public events. Applied Cognitive Psychology, 21, 1005-1022.

Sangero, B. (2018). Safety from false confessions. SSRN Electronic Journal. doi:10.2139/ssrn. 3362754

Shawyer, A., Milne, B., \& Bull, R. (2009). Investigative interviewing in the UK. In T. Williamson, B. Milne, \& R. Bull (Eds.), International developments in investigative interviewing (pp. 24-38). Devon, England: Willan. 
Skeem, J. L., Douglas, K. S., \& Lilienfeld, S. O. (2009). Psychological science in the courtroom: Consensus and controversy. New York: Guilford Press.

Stewart, J. M., Woody, W. D., \& Pulos, S. (2018). The prevalence of false confessions in experimental laboratory simulations: A meta-analysis. Behavioral Sciences \& the Law, 36(1), 12-31. doi:10.1002/bsl.2327

Stewart, J. M., Woody, W. D., Pulos, S., \& Forrest, K. D. (2012). Meta-analysis of confession research. Presented at the annual meeting of the American Psychology-Law Society, San Juan, Puerto Rico.

Trainum, J. L. (2016). How the police generate false confessions: an inside look at the interrogation room. Lanham, MD: Rowman \& Littlefield.

Torkildson, J., \& Kassin, S. M. (2008). Inside interrogation: The outright lie, the bluff, and false confessions. In Meeting of the American Psychology-Law Conference, Jacksonville, FL.

Wade, K. A., Garry, M., Read, J. D., \& Lindsay, D. S. (2002). A picture is worth a thousand lies: Using false photographs to create false childhood memories. Psychonomic Bulletin \& Review, 9(3), 597-603. doi:10.3758/bf03196318

Wakefield, H., \& Underwager, R. (1998). Coerced or nonvoluntary confessions. Behavioral Sciences and the Law, 16, 423-440.

Wilford, M. M., \& Wells, G. L. (2018). Bluffed by the dealer: Distinguishing false pleas from false confessions. Psychology, Public Policy, and Law, 24(2), 158.

Woody, W. D., \& Forrest, K. D. (2009). Effects of false-evidence ploys and expert testimony on jurors verdicts, recommended sentences, and perceptions of confession evidence. Behavioral Sciences \& the Law, 27(3), 333-360. doi:10.1002/bsl.865 